UNIVERSIDADE DE SÃO PAULO

Faculdade de Zootecnia e Engenharia de Alimentos

FABRICIO CALDAS ALBUQUERQUE

Concurso Completo de Equitação: um estudo aplicado para a organização de competições oficiais internacionais de 2 estrelas

Pirassununga 
Concurso Completo de Equitação: um estudo aplicado para a organização de competições oficiais internacionais de 2 estrelas

(VERSÃO CORRIGIDA)

Dissertação apresentada à Faculdade de Zootecnia e Engenharia de Alimentos da Universidade de São Paulo, como parte dos requisitos para obtenção do Título de Mestre em Ciências com ênfase em Gestão e Inovação na Indústria Animal.

Área de Concentração: Gestão e Inovação da Indústria Animal.

Orientadora: Profa. Dra. Roberta Ariboni Brandi 
Ficha catalográfica elaborada pelo

Serviço de Biblioteca e Informação, FZEA/USP, com os dados fornecidos pelo(a) autor(a)

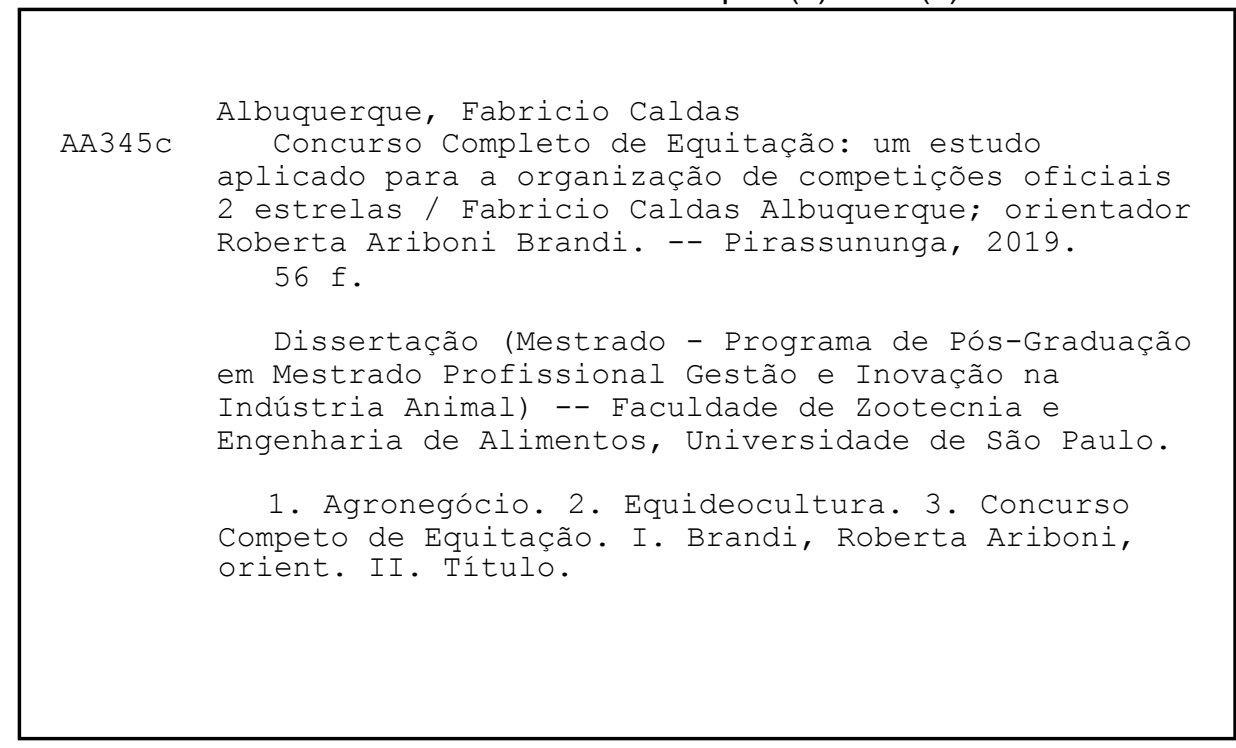

Permitida a cópia total ou parcial deste documento, desde que citada a fonte - o autor 


\section{Concurso Completo de Equitação: um estudo aplicado para a organização de competições oficiais internacionais de 2 estrelas}

Dissertação apresentada à Faculdade de Zootecnia e Engenharia de Alimentos da Universidade de São Paulo, como parte dos requisitos para a obtenção do Título de Mestre em Ciências com ênfase em Gestão e Inovação na Indústria Animal.

Área de Concentração: Gestão e Inovação na Indústria Animal

Data de aprovação: 25/ 06/ 2019

Banca Examinadora:

Profa. Dra. Roberta Ariboni Brandi - FZEA - USP - Orientadora

Profa. Dra. Lina Maria Wehrle Gomide - UNESP (externa ao Programa/ USP)

Profa. Dra. Roberta Carvalho Basile - UNESP (externa ao Programa/ USP)

Profa. Dra. Fabiana Cunha Viana Leonelli - USP - (interna ao Programa/ USP) 


\section{DEDICATÓRIA}

Aos meus pais, Fatima e Eliaci, pela educação que me proporcionaram e apoio ao longo da minha vida.

Aos meus filhos, Frederico e Guilherme, por sempre despertarem o melhor em mim. 


\section{AGRADECIMENTOS}

À minha família, por todo o exemplo e apoio que sempre me proporcionaram.

Aos meus amigos pela compreensão, incentivo e pelo estímulo ao longo de todo o processo.

À minha atual orientadora, Profa. Dra. Roberta Ariboni, pelas importantes e oportunas orientações, sempre direcionando o trabalho para a direção correta e contribuindo assim, para o aprimoramento constante do mesmo.

À Prof Dra. Fabiana Leonelli por ter sido minha primeira orientadora e sempre ter acrescentado orientações úteis ao desenvolvimento do trabalho.

Aos professores do Programa de Pós-Graduação em Gestão e Inovação da Indústria Animal, por todo conhecimento compartilhado.

À Sra, Mirla Neves da Associação Brasileira de Hipismo Rural (ABHIR) e ao Sr. Tiago Aiello Padilha da Federação Paulista de Hipismo (FPH) pela disponibilização de dados e atenção que tiveram permitindo assim, o enriquecimento do presente trabalho.

A Deus, por sempre me acompanhar e me levar em frente.

A todos vocês, o meu agradecimento. 


\section{LISTA DE FIGURAS}

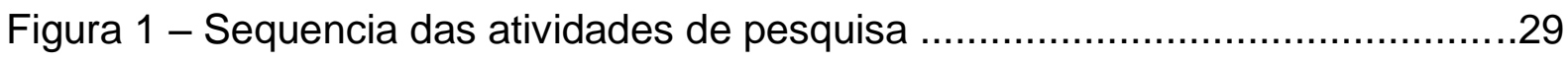

Figura 2 - Organograma de solicitação para a realização da competição..................32

Figura 3 - Organograma de hierarquia dos grupos envolvidos para a realização da

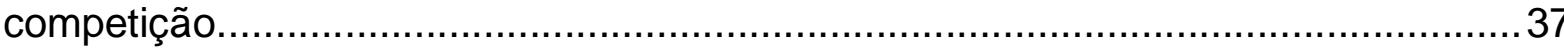

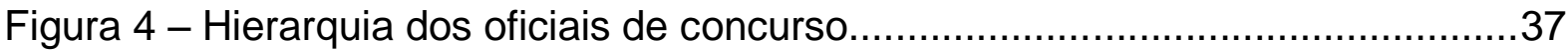




\section{LISTA DE QUADROS}

Quadro 1 - Reprises de adestramento para CCE - Anexo A do Regulamento de CCE da FEI - 2019.

Quadro 2 - Dimensões máximas para os obstáculos do percurso da prova de crosscountry - Anexo B do Regulamento de CCE da FEI - 2019

Quadro 3 - Percurso da prova de cross-country no formato longo (Concurso Completo Internacional): distâncias, número de esforços e velocidade do percurso Anexo B do Regulamento de CCE da FEI - 2019.

Quadro 4 - Prova de cross-country no formato curto (Concurso Internacional Combinado): distâncias, número de esforços e velocidade do percurso - Anexo B do Regulamento de CCE da FEI - 2019.... 24

Quadro 5 - Prova de salto: distâncias, velocidades e número de esforços - Anexo C do Regulamento de CCE da FEI - 2019.

Quadro 6 - Oficiais de concurso necessários para a montagem de uma competição do formato longo (Concurso Completo Internacional). 


\section{LISTA DE ABREVIATURAS E SIGLAS}

\begin{tabular}{ll} 
ABHIR & Associação Brasileira de Hipismo Rural \\
AIE & Anemia Infecciosa Equina \\
CBH & Confederação Brasileira de Hipismo \\
CCE & Concurso Completo de Equitação \\
CCl & Concurso Completo Internacional \\
CIC & Concurso Internacional Combinado \\
COI & Comitê Olímpico Internacional \\
DP & Desenhador de Percurso \\
DT & Delegado Técnico \\
FEI & Federação Equestre Internacional \\
FPH & Federação Paulista de Hipismo \\
GTA & Guia de Transporte Animal \\
JC & Júri de Campo \\
m & metro (s) \\
Máx & Máximo \\
Min & Mínimo \\
Min & minuto (s) \\
mpm & metros por minuto \\
Nr & Número \\
PP & Ponto (s) Perdido (s) \\
USEA & United States Eventing Association \\
\hline
\end{tabular}




\section{SUMÁRIO}

RESUMO

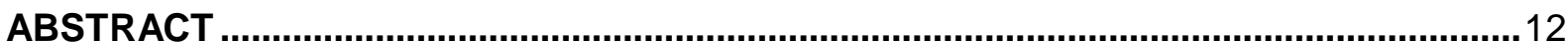

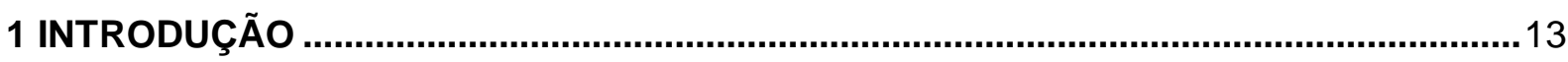

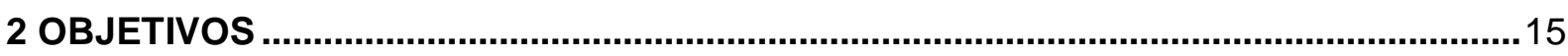

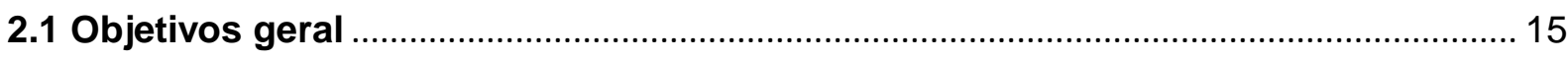

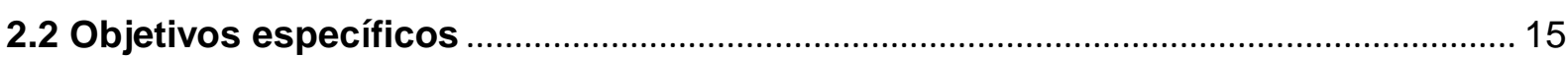

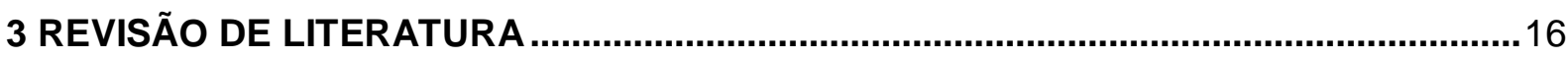

3.1 A contribuição do CCE no agronegócio cavalo ....................................................... 16

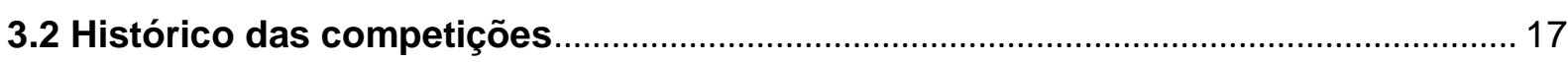

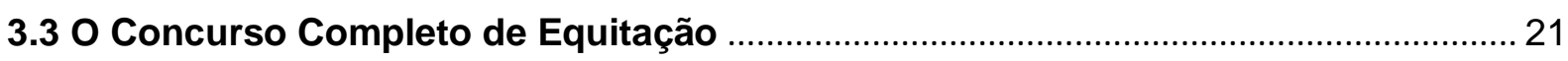

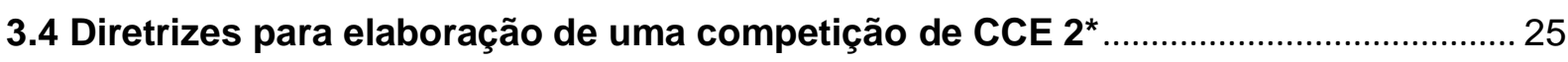

4 MATERIAL E MÉTODOS ........................................................................................29

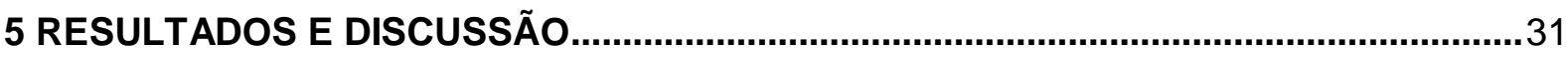

5.1 Estruturação de organograma para realização de competições internacionais de CCE 2*

5.2 Necessidades para a realização da competição e suas características

5.2.1 Descrição das condições indispensáveis para o recebimento e acolhimento dos animais

5.2.2 Atendimento ao cavaleiro, oficiais de concurso, comissão organizadora, equipe de

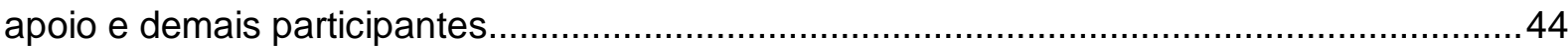

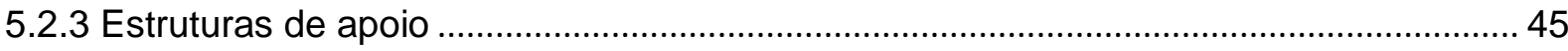

5.3 Estruturação de potencial de negócio e a atratividade do segmento equestre para

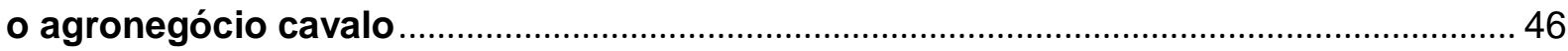

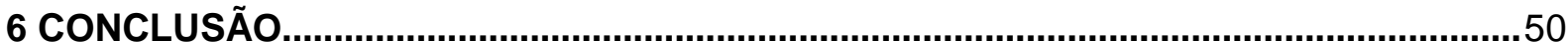

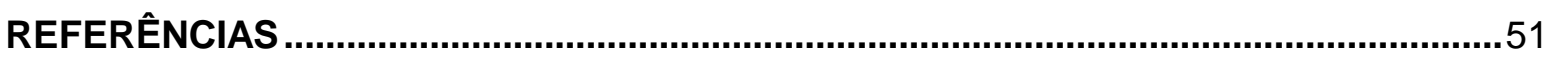




\section{RESUMO}

ALBUQUERQUE, F. C. Concurso Completo de Equitação: um estudo aplicado para a organização de competições oficiais internacionais de 2 estrelas. $56 \mathrm{f}$. Qualificação (Mestrado) - Faculdade de Zootecnia e Engenharia de Alimentos, Universidade de São Paulo, Pirassununga, 2019.

Com o objetivo de identificar, elencar e elucidar os elementos do organograma da realização das competições internacionais de CCE 2 estrelas e de determinar a estrutura mínima necessária para a realização destas competições para o agronegócio cavalo, uma pesquisa exploratória explicitou o problema a ser estudado, utilizando-se para sua elaboração, dados primários, conhecimento tácito do pesquisador (uma vez que o mesmo também tem formação de oficial de concurso) e dados secundários de diretrizes organizacionais disponibilizados pela FEl. Este é um trabalho inédito que sistematizou as orientações dos regulamentos da $\mathrm{CBH}$ e da $\mathrm{FEI}$, gerando informações instrutivas e organizadas que permitem a estruturação das competições internacionais de CCE 2 estrelas, a ação específica e a hierarquização dos oficiais, permitindo a compreensão da organização de uma competição de CCE. É um documento que reúne informações práticas enriquecidas pela vivência do autor. A movimentação econômica do CCE atinge cifras relevantes e se faz necessário estruturar este potencial de negócio para que ele se torne atrativo para investimentos não só econômicos, mas também na capacitação de profissionais para que possam atender o maior público possível, tanto ligado ao cavalo, como também a sociedade que poderá ter acesso a um grande evento.

Palavras-chave: agronegócio, hipismo, oficiais de concurso, organogramas. 


\begin{abstract}
ALBUQUERQUE, F. C. Eventing: a study applied to the organization of official 2 stars international competitions 56f. Qualifying (Master's degree). Faculdade de Zootecnia e Engenharia de Alimentos, Universidade de São Paulo, Pirassununga, 2019.

In order to identify, list and elucidate the elements of the organizational chart related to the Eventing 2 stars international competitions and to determinate the minimum structure required to the realization of such competitions for the horse agribusiness, an exploratory research highlighted the problem that need further investigation, using for this purpose, primary data, tacit knowledge of the researcher (since he proper has formation on eventing official) and secondary data based on organizational guidelines provided by FEl. This is an unpublished work that standardizes the guidelines of the $\mathrm{CBH}$ and $\mathrm{FEl}$ regulations, and deliveries instructional and organized information that allow the establishment of international competitions of CCE 2 stars and the specific action and hierarchy of officers; allowing a more comprehensive understanding about the development of a CCE competition. It is a document that gathers practical information enriched by the author's experience. The economy involved on the CCE field is relevant and it is necessary to structure this business potential so it can become attractive not only to economic investments, but also in what concerns the training of professionals, so they can serve the largest possible audience. In this sense, this study is of great value not only to the horse agribusiness, but also to the society, that will have access to large and well-organized events.
\end{abstract}

Keywords: agribusiness, equestrianism, eventing officers, organizational charts. 


\section{INTRODUÇÃO}

O agronegócio cavalo brasileiro tem apresentado nos últimos anos movimentação anual na cifra de $R \$ 8,5$ bilhões (LIMA; CINTRA, 2015), possui uma tropa com aproximadamente 5,5 milhões de equinos sendo assim, o maior rebanho da América Latina (FOOD AND AGRICULTURE ORGANIZATION OF THE UNITED NATIONS, 2018).

Dentro do contexto do agronegócio cavalo no Brasil merecem destaque as competições equestres em suas diversas modalidades como as competições de rédeas, atrelagem, adestramento, salto, Concurso Completo de Equitação (CCE), entre outras (LIMA; CINTRA, 2015); provas estas regulamentadas pela Confederação Brasileira de Hipismo $(\mathrm{CBH})$ e, internacionalmente, pela Federação Equestre Internacional (FEI).

Dentre estas competições, destaca-se o CCE pela complexidade de sua organização, pois em uma mesma competição, com um mesmo cavalo, são realizadas provas de adestramento, salto e prova de cross-country ( $F E I, 2019 c)$. A realização destas competições só é possível com a mobilização de grande infraestrutura física (picadeiros de adestramento, percurso de cross-country e pista de salto) e de recursos humanos especializados. A demanda para a organização das competições em seus diversos níveis é praticamente a mesma, devendo ser consideradas especificidades quanto às normas de cada uma das três provas que compõe a competição.

São atores principais do organograma desta modalidade os cavaleiros, cavalos, comissão organizadora, proprietário do local onde será realizada a competição, oficiais de concurso, veterinários, tratadores, "pistinhas", ferradores e equipe médica, grupo mínimo necessário sem o qual não se realiza uma competição oficial, seja nacional ou internacional $(\mathrm{CBH}, 2017)$. Para o planejamento destas competições, informações indispensáveis sobre cada um dos elementos do organograma precisam ser determinadas a fim de garantir a qualidade e execução do evento (PAYNE, 2006).

Atualmente não existem empresas para organização destes eventos e estas informações não estão organizadas em um documento e sim pulverizadas em regulamentos e grande parte está no conhecimento tácito de pessoas do meio. Como não se tem formação especifica e organização, a caracterização desta 
atividade como agronegócio é dificultada. A atribuição de valores é subjetiva e não há estimulo para novos profissionais se capacitarem na área (POIT, 2013)

A literatura sobre a área é escassa e a demanda de informações sistematizadas é necessária, não só para compreender a organização e a montagem de um programa de competição, mas também, para consolidar a sua organização como uma atividade lucrativa do agronegócio que motive novos profissionais a entrarem na área.

Neste sentido, o presente estudo teve como objetivo identificar e elucidar os elementos do organograma da realização das competições internacionais de CCE do nível 2 estrelas, bem como a estrutura mínima necessária para a realização desta atividade visando demonstrar a atratividade do segmento de competições equestres para o agronegócio cavalo. 


\section{OBJETIVOS}

\subsection{Objetivo geral}

Identificar, elencar e elucidar os elementos do organograma da realização das competições internacionais de CCE de 2 estrelas, bem como a estrutura mínima necessária para a sua realização visando demonstrar a atratividade do segmento de competições equestres para o agronegócio cavalo.

\subsection{Objetivos específicos}

- Analisar as orientações/ instruções da CBH e da FEl;

- Estruturar o organograma da realização de uma competição de CCE;

- Confeccionar material inédito sobre a organização de uma competição de CCE;

- Pontuar a movimentação de recursos (não mensurados);

- Estruturação de potencial de negócio; e

- Demonstrar a atratividade do segmento de competições equestres para o agronegócio cavalo. 


\section{REVISÃO DE LITERATURA}

\subsection{A contribuição do CCE no agronegócio cavalo}

Segundo a FAOSTAT (2018), a população mundial de equinos é de cerca de 60.566.601, sendo que 5.501.872 cabeças estão alocadas no Brasil. As maiores populações nacionais estão respectivamente nos estados de Minas Gerais, Rio Grande do Sul, Bahia, Goiás e São Paulo (LIMA; CINTRA, 2015). Este mesmo estudo informa que a população de equinos destinada a lazer e esporte em 2014 era de 1.100 .000 enquanto que para lida perfazia 3.900 .000 , efetivo que pode ter ser valor influenciado pela forma de obtenção dos dados.

O agronegócio cavalo tem como característica ser um complexo e não uma atividade linear, pois as atividades, muitas vezes, tem dupla função, de consumidor final e de fornecedor, além de agregar não só as atividades diretamente ligadas ao cavalo como também atividades complementares com articulações intersetoriais (LIMA; SHIROTA; BARROS, 2006).

A renda gerada no Complexo do Agronegócio do Cavalo no Brasil, em valores de abril de 2015 , totalizou $\mathrm{R} \$ 16,15$ bilhões com 607.329 pessoas ocupadas diretamente, além de 2.429.316 empregos indiretos totalizando com isso, 3 milhões de pessoas ocupadas. Quando se considera apenas a população de cavalos de esporte e lazer a movimentação econômica é da cifra de $R$ \$ 5,84 bilhões (LIMA; CINTRA, 2015).

Pouco se informa sobre a movimentação econômica das competições equestres. Como os estudos sobre o tema são escassos ou inexistentes, esta informação não é obtida e deixa-se de conhecer um potencial mercado.

A Federação Paulista de Hipismo (FPH) tem filiados 2007 cavalos e 1776 cavaleiros, sendo que 71 destes cavaleiros e 18 cavalos estão na modalidade de $\mathrm{CCE}^{1}$. Como um cavalo inscrito na modalidade de salto, pode ser utilizado na modalidade de CCE, o numero total é maior. Na Associação Brasileira de Cavaleiros de Hipismo Rural (ABHIR), 3000 cavaleiros estão filiados, 34 deles na modalidade CCE. A movimentação econômica gerada pela filiação de cavalos e cavaleiros é de cifras consideráveis, mas pouco conhecidas. $A$ taxa de anuidade da $A B H I R$ é de $R \$$ 440,00, para competições acima de 0,70 metros (ABHIR, 2019).

\footnotetext{
${ }^{1}$ Dado fornecido a Profa. Dra. Roberta Brandi pela FPH em janeiro de 2019.
} 
Não são conhecidas empresas de organização de competição e todas as informações estão a cargo de pessoas diretamente envolvidas na atividade, o que torna difícil a obtenção de informações científicas sobre o tema.

\subsection{Histórico das competições}

O CCE surgiu da necessidade de preparação dos exércitos europeus para a guerra, quando o cavalo era empregado em grande escala nos combates. Assim, aprimorou-se o treinamento dos conjuntos (animal e cavaleiro) para que fosse além da instrução militar a cavalo. Surgiram as competições a cavalo com o intuito de incentivar o desenvolvimento técnico e físico de cavalos e cavaleiros. Inicialmente, no século XIX, as competições eram grandes marchas realizadas pelos principais exércitos europeus buscando desenvolver a resistência física e moral tanto do cavalo, como do cavaleiro. Eram realizadas marchas onde o conjunto marchava entre 80 e 100 quilômetros por dia, durante 4 ou 5 dias consecutivos (CAVALCANTI, 2005).

No Brasil, o cavalo foi inicialmente introduzido pelos portugueses para ser utilizado no trabalho da lavoura e na lida com o gado. Posteriormente, foi utilizado pelos bandeirantes em sua marcha desbravadora para a região oeste do país, delineando assim, as novas fronteiras nacionais. A primeira competição hípica que se tem notícia em solo nacional aconteceu em abril de 1641 em Maurícea, hoje cidade de Recife - Pernambuco, por iniciativa do príncipe holandês João Maurício de Nassau e foi o Torneio de Cavalaria (FERREIRA, 1999). O cavalo também foi utilizado em cavalgadas, corridas, pelo Exército Brasileiro em exercícios no terreno e combates e pelas Forças Públicas estaduais (embrião das atuais polícias militares estaduais). A prática da equitação acadêmica é somente iniciada no ano de 1863, pelo brasileiro Luiz Jácome de Abreu e Souza, que havia estudado os princípios equestres com o duque de Newcastle, na Inglaterra e fundou diversos jockeys clubs e clubes hípicos pelo país (MORGADO, 1990).

O hipismo foi incluído como demonstração nos Jogos Olímpicos de 1900 em Paris, na França (CAVALCANTI, 1993). O primeiro Campeonato de Cavalo d'Armas - competição muito semelhante ao atual CCE - foi realizado no ano de 1902 na França e passou a fazer parte efetivamente do programa olímpico, nos Jogos Olímpicos de 1912 em Estocolmo na Suécia (BRASIL, 2017). 
A partir do ano de 1921, com a criação da FEI na cidade de Lausanne na Suiça, a modalidade passa a ser regulamentada por esta entidade.

A criação da FEl tem importância significativa na padronização de procedimentos e na criação de protocolos, pois, a partir deste momento, existiu uma preocupação cada vez maior para que as competições fossem realizadas dentro de um mesmo padrão técnico, independente do local onde ocorram. A FEl coordena sete modalidades equestres: Adestramento, Atrelagem, Concurso Completo de Equitação (CCE), Enduro, Rédeas, Salto e Volteio (FEl, 2019e).

A chegada da modalidade do Cavalo d'Armas no Brasil ocorreu por meio dos cavaleiros do Exército Brasileiro, principalmente por meio da Missão Militar Francesa que ocorreu no início da década de 1920, após o término da Primeira Guerra Mundial. Em 20 de abril de 1922, no Rio de Janeiro é criada o Centro de Formação de Oficiais Instrutores de Equitação, embrião da Escola de Equitação do Exército, estabelecimento responsável por ser um dos difusores da doutrina equestre no País até os dias de hoje (MCCANN, 2007).

A primeira competição de CCE disputada no Brasil foi organizada pelo Exército em 1922, época em que ainda era conhecida como Cavalo d'Armas (Military para os alemães e Three Day Event para ingleses e americanos) e compreendia quatro provas, a de adestramento - que simulava a necessidade de realizar os movimentos em uma parada militar mostrando a elegância e a obediência do cavalo ao cavaleiro, a de steeple-chase - procurava verificar se o animal possuía resistência para a realização de grandes deslocamentos e para as cargas de cavalaria (realizadas ao galope), a de fundo - onde o cavalo deveria demonstrar coragem, força e energia para saltar obstáculos rústicos no campo e por último, a de salto - mostrando que após as fortes exigências da steeple-chase e do crosscountry, o cavalo ainda estava saudável e em condições de realizar um percurso de salto sobre obstáculos móveis.

Cada uma destas provas era disputada em um dia diferente e consecutivamente (FERREIRA, 1999). Cabe ressaltar que, incialmente, a competição só era permitida para militares do sexo masculino sendo aberta a cavaleiros não militares somente no ano de 1924 e para amazonas no ano de 1964.

Outro marco importante na história do hipismo no Brasil é a criação da Confederação Brasileira de Hipismo, no dia 19 de dezembro de 1941, que possui além das sete modalidades existentes na FEI, a equitação especial (LIMA; CINTRA, 
2015). A CBH possui atualmente vinte e uma federações estaduais e a Comissão de Desportos do Exército (CBH, 2018a). Neste mesmo ano, a competição passou a ser conhecida no Brasil como Concurso Completo de Equitação e os eventos começaram a seguir a regulamentação da $\mathrm{FEl}$.

A primeira participação de uma equipe do Brasil no hipismo nos Jogos Olímpicos ocorreu no ano de 1948, nos Jogos Olímpicos de Londres, Inglaterra. $\mathrm{Na}$ modalidade Cavalo d'Armas, o Capitão Aécio Morrot montando Guapo conseguiu na competição, o sétimo lugar individual, sendo este até hoje o melhor resultado obtido pelo país na modalidade (FERREIRA, 1999).

Várias modificações foram realizadas na competição durante 0 desenvolvimento da modalidade, mas sempre procurando manter a essência do esporte. Segundo Dutton (2013), uma das maiores mudanças ocorreu no formato da competição. Nos anos de 2004 e 2005 o formato completo ou longo (composto por 4 fases: A e C - estradas e caminhos, B - steeple-chase e D - cross-country) foi modificado e assim a extensão da prova de cross-country foi sensivelmente encurtada (permanecendo somente a fase $\mathrm{D}$ ).

Esta mudança foi influenciada em grande parte pelo Comitê Olímpico Internacional (COI) que ameaçava retirar o CCE do programa olímpico, pois, a prova de fundo necessitava de grande áreas (para a fase $\mathrm{A}$ e $\mathrm{C}$ que eram realizadas ao trote) e grandes gastos para a construção das quatro fases da prova (principalmente na preparação do piso - grama). Além disto, a prova de fundo composta pelas 4 fases exigia grande preparação dos animais e era extremamente extenuante fisicamente (tinha a duração total de pouco mais de uma hora) para o conjunto.

Estas características geravam grande desgaste e uma série de lesões nos animais tornando assim a modalidade CCE, alvo de muitas críticas por parte das entidades envolvidas com o bem estar animal.

Os últimos grandes eventos realizados no formato "clássico" (completo) foram os Jogos Olímpicos de 2000 em Sidnei - Austrália e os Jogos Equestres Mundiais em Jerez de la Frontera - Espanha em 2002 onde apenas 58,75\% dos conjuntos que iniciaram na prova de adestramento concluíram a prova de salto no último dia (os conjuntos foram eliminados no cross-country ou em decorrência dele claudicações e desgaste físico excessivo) e assim, completaram toda a competição (CBH, 2003). 
As últimas competições no nível 4 estrelas (maior dificuldade e atualmente com a designação de $5^{*}$ ) neste formato foram realizados no ano de 2005 , em Badminton e Burghley na Inglaterra e em Kentucky nos Estados Unidos. Também foram adotadas várias mudanças para a prova de cross-country como:

- dispositivos de segurança para os obstáculos fixos (como pinos e grampos de segurança, que após sofrerem um choque com alguma parte do cavalo, são desmontados, evitando assim uma lesão de maior gravidade para o cavalo e/ ou cavaleiro);

- obstáculos deformáveis (sofrem deformação após o choque de uma parte do animal com o mesmo);

- obstáculos com maior exigência técnica (exigem mais precisão do conjunto para a realização do salto e consequentemente aumentam a segurança por exigirem um maior controle do cavalo por parte do cavaleiro);

- coletes protetores para o tronco e pescoço para cavaleiros com airbags (são acionados - inflados - em caso de queda do cavaleiro);

- protetores para os membros dos cavalos (capazes de absorver o choque em caso de pancadas com os obstáculos fixos, mitigando assim, o risco de lesões);

- disponibilização de ambulâncias veterinárias (permitindo quando necessário, o atendimento do animal no local onde ocorreu o acidente); e

- aprimoramento dos protocolos para evacuação médica dos cavaleiros (helicópteros para evacuação, ambulâncias com melhores equipamentos e maior disponibilidade de médicos).

Houve por parte da FEl e das confederações nacionais uma preocupação para que fosse registrados um número maior de estatísticas e relatórios para que fossem aprimorados, após a sua devida análise, procedimentos com o intuito de aumentar a segurança (UNITED STATES EVENTING ASSOCIATION, 2012).

Os diversos regulamentos da modalidade também vêm sendo atualizados, muitas vezes anualmente, visando exigir dos cavaleiros e dos oficiais de concurso, maiores preocupações com o bem estar animal na realização da competição. Assim, foram elaboradas regras como o artigo 525.1 do Regulamento de CCE da FEI (FEI, 2019c) com o intuito de evitar a equitação perigosa (situação que ocorre quando o conjunto realiza saltos nos obstáculos com muita ou pouca velocidade, sem controle de sua montada para a realização do salto ou no intervalo entre os obstáculos, realiza saltos perigosos, continua saltando o percurso após ter sido eliminado por 
três desobediências, coloca em risco o público durante a condução do cavalo no percurso, salta obstáculos que não fazem parte do obstáculo, atrapalha outro conjunto que também esteja realizando o percurso e não segue as orientações dos oficiais de concurso) e o artigo 526.1 (também do Regulamento de CCE da FEI) sobre abuso do cavalo, que ocorre quando o cavaleiro deixa de respeitar os preceitos do bem estar animal como continuar o percurso quando o animal está esgotado fisicamente, com claudicação, após uso excessivo de espora e/ ou chicote e sangue no flanco, na garupa ou na boca.

Outro artigo importante do Regulamento de CCE da FEl é o 517 (FEl, 2019c) que define um sistema de qualificação, que em linhas gerais exige que o cavaleiro e o cavalo obtenham um índice mínimo técnico em cada uma das três provas para que seja autorizado a realizar uma competição de nível superior.

O objetivo principal com todas estas mudanças é proporcionar maior segurança ao cavalo e ao cavaleiro reduzindo assim acidentes graves ou fatais, principalmente na prova de cross-country, suas consequências negativas para 0 conjunto e proporcionar assim, melhores imagens para a divulgação do esporte (PAYNE, 2006).

\subsection{O Concurso Completo de Equitação}

O CCE é a segunda modalidade com mais praticantes na FEI (CAVALCANTI, 2017). Durante toda a competição não ocorre substituição de cavalo e/ou cavaleiro. Homens e mulheres competem em condições de igualdade, tanto individual como por equipes, assim como éguas, cavalos castrados e garanhões disputam em condições de igualdade (FEI, 2019c).

A competição pode ser realizada no formato curto ou longo. Nos dois formatos $\mathrm{O}$ adestramento é obrigatoriamente a primeira prova a ser realizada na competição (CBH, 2006).

A competição no formato curto pode ser realizada em um (conhecido também como one-day-event), dois ou três dias. Após a prova de adestramento pode ser realizada o cross-country (que tem uma extensão menor e pode ter um número de esforços menor do que o do formato longo) ou o salto, com a mesma dificuldade da competição do formato longo (DUTTON, 2013).

No formato longo é obrigatório que a competição aconteça em três ou quatro dias. O adestramento é realizado no primeiro e segundo dia (caso a duração da 
competição seja de quatro dias), o cross-country no segundo (ou terceiro, caso sejam destinados dois dias ao adestramento) e o salto no terceiro ou quarto dia (FEl, 2019c).

Para os eventos internacionais o nível de dificuldade das competições é definida somente por estrelas sendo o 1 estrela $\left(^{*}\right)$ o nível de menor dificuldade, dedicado aos cavalos e/ ou cavaleiros iniciantes em competições internacionais e o $5^{\star}$ o nível de maior dificuldade (as provas de $5^{\star}$ estrela são obrigatoriamente no formato completo, de acordo com o regulamento da FEI). Não existem eventos internacionais inferiores ao nível de dificuldade $1^{*}$ - por não serem previstos no Regulamento FEl. Eventos abaixo deste nível só são realizados em competições nacionais regulamentadas pela $\mathrm{CBH}$ (FEI, 2019c).

Para os eventos nacionais, que são regidos pela $\mathrm{CBH}$, além das competições de $1^{*}, 2^{*}, 3^{*}$ e $4^{*}$, são realizadas nos seguintes níveis de dificuldade (altura dos obstáculos na prova de cross-country e salto): Nível 60 centímetros (N60), Nível 80 centímetros (N80) e Nível 1 metro (NI). Nas competições nacionais, o nível $4^{*}$ é o que apresenta maior exigência técnica e física para os conjuntos, não sendo realizadas competições no nível $5^{\star}(\mathrm{CBH}, 2006)$.

Segundo o Regulamento da FEI (FEl, 2019c), O CCE ou Triatlo Equestre é composto por de três provas:

- prova de adestramento: onde ocorre a execução de uma reprise (sequência de movimentos ou figuras exigidas para a realização desta prova, onde são realizados movimentos ao passo, trote e galope) em um picadeiro com dimensões de 20 metros por 60 metros. Cada figura recebe dos juízes da prova uma nota entre 0 e 10, sendo a nota 10 para a perfeita execução da figura e 0 quando a figura não é executada (MORGADO, 1990). Ao final todas as notas recebidas pelo conjunto são somadas e subtraídas do valor máximo total possível (número total de figuras multiplicadas por 10 - nota máxima), sendo que esta diferença é o número de Pontos Perdidos (PP) que o conjunto possui após a primeira prova (adestramento), de forma que todas as penalizações recebidas posteriormente pelo conjunto, nas provas de cross-country e salto são adicionadas a esta pontuação; 
Quadro 1 - Reprises de adestramento para CCE - Anexo A do Regulamento de CCE da FEI $-2019$

\begin{tabular}{|c|c|c|}
\hline Nível & Reprise & Duração de execução em minutos e segundos \\
\hline Uma estrela & Reprise $1^{*}-2018$ & Aproximadamente 4 e 30 \\
\hline \multirow{2}{*}{ Duas estrelas } & Reprise $2^{*}$ A - 2015 & Aproximadamente 4 e 30 \\
\hline & Reprise $2^{*} B-2015$ & Aproximadamente 4 e 00 \\
\hline \multirow{2}{*}{ Três estrelas } & Reprise 3* A - 2015 & Aproximadamente 5 e 00 \\
\hline & Reprise $3^{*} B-2015$ & Aproximadamente 5 e 00 \\
\hline \multirow{2}{*}{ Quatro estrelas } & Reprise $4^{*} \mathrm{~A}-2015$ & Aproximadamente 5 e 00 \\
\hline & Reprise $4^{*} B-2015$ & Aproximadamente 5 e 00 \\
\hline \multirow{2}{*}{ Cinco estrelas } & Reprise $5^{*} \mathrm{~A}-2017$ & Aproximadamente 5 e 00 \\
\hline & Reprise $5^{\star} \mathrm{B}-2017$ & Aproximadamente 5 e 00 \\
\hline
\end{tabular}

Fonte: FEI. Eventing Rules - 25th edition effective 1st January 2019.

- prova de cross-country: um percurso no campo (terreno variado) composto por obstáculos fixos (altura de até 1,10 metros e largura na parte superior de até 1,40 metros - competição de $2^{*}$ ) como troncos, muros, banquetas, negativas, sebes, água e buracos. O piso é em sua maior parte constituído de grama. O conjunto é penalizado caso não realize o percurso dentro de um tempo concedido $(0,4 \mathrm{PP}$ por segundo iniciado a mais do tempo concedido). Este tempo é obtido dividindo-se a distância total do percurso (entre 3640 e 4680 metros no formato completo do $2^{*}$ ) pela velocidade da prova (520 metros por minutos no $2^{*}$ ).

Também é penalizado caso tenha alguma desobediência (como refugos ou desvios - situação em que o cavalo não salta um obstáculo previsto constante do percurso) sendo assim penalizado com 20 PP por cada desobediência (caso ocorra uma segunda desobediência no mesmo obstáculo, esta será penalizada com 40 PP. Se a desobediência ocorrer em outro obstáculo será penalizado novamente com 20 PP) e sendo eliminado da competição após a 3ª desobediência (FEI, 2019c); e 
Quadro 2 - Dimensões máximas para os obstáculos do percurso da prova de cross-countryAnexo B do Regulamento de CCE da FEI - 2019

\begin{tabular}{|c|c|c|c|c|c|}
\hline Parâmetro/ Nível da Competição & $\mathbf{1}^{\boldsymbol{*}}$ & $\mathbf{2}^{\boldsymbol{*}}$ & $\mathbf{3}^{\boldsymbol{*}}$ & $\mathbf{4}^{\boldsymbol{*}}$ & $\mathbf{5}^{\boldsymbol{*}}$ \\
\hline Altura fixa em metros & 1.05 & 1.10 & 1.15 & 1.20 & 1.20 \\
\hline Altura com Sebe em metros & 1.25 & 1.30 & 1.35 & 1.40 & 1.45 \\
\hline Largura superior em metros & 1.20 & 1.40 & 1.60 & 1.80 & 2.00 \\
\hline Largura na base em metros & 1.80 & 2.10 & 2.40 & 2.70 & 3.00 \\
\hline Largura sem altura em metros & 2.40 & 2.80 & 3.20 & 3.60 & 4.00 \\
\hline Negativa em metros & 1.40 & 1.60 & 1.80 & 2.00 & 2.00 \\
\hline
\end{tabular}

Fonte: FEl. Eventing Rules - 25th edition effective 1st January 2019.

Quadro 3 - Percurso da prova de cross-country no formato longo (Concurso Completo Internacional): distâncias, número de esforços, velocidade do percurso - Anexo B do Regulamento de CCE da FEI 2019

\begin{tabular}{|c|c|c|c|c|c|c|}
\hline \multicolumn{2}{|c|}{ Nível } & $\mathbf{1}^{\boldsymbol{*}}$ & $\mathbf{2}^{\boldsymbol{*}}$ & $\mathbf{3}^{\boldsymbol{*}}$ & $\mathbf{4}^{\boldsymbol{*}}$ & $\mathbf{5}^{\boldsymbol{*}}$ \\
\hline \multirow{2}{*}{$\begin{array}{c}\text { Distância em } \\
\text { metros }\end{array}$} & Mínima & 2000 & 3640 & 4400 & 5700 & 6270 \\
\cline { 2 - 7 } & Máxima & 3000 & 4680 & 5500 & 6270 & 6840 \\
\hline $\begin{array}{c}\text { Número de } \\
\text { Esforços }\end{array}$ & Mínimo & 20 & 25 & 30 & 35 & 40 \\
\cline { 2 - 7 } & Máximo & 25 & 30 & 35 & 40 & 570 \\
\hline \begin{tabular}{c} 
Velocidade em metros por \\
\multicolumn{2}{c|}{ minuto }
\end{tabular} & 500 & 520 & 550 & 570 & 11 \\
\hline \multirow{2}{*}{$\begin{array}{c}\text { Tempo em } \\
\text { minutos }\end{array}$} & Mínima & 4 & 7 & 8 & 10 & 12 \\
\cline { 2 - 7 }
\end{tabular}

Fonte: FEl. Eventing Rules - 25th edition effective 1st January 2019.

Quadro 4 - Prova de cross-country no formato curto (Concurso Internacional Combinado): distâncias, número de esforços, velocidades do percurso - Anexo B do Regulamento de CCE da FEI $-2019$

\begin{tabular}{|c|c|c|c|c|}
\hline \multicolumn{2}{|c|}{ Nível } & $2^{*}$ & $3^{*}$ & $4^{*}$ \\
\hline \multirow{2}{*}{$\begin{array}{c}\text { Distância em } \\
\text { metros }\end{array}$} & Mínima & 2600 & 3025 & 5700 \\
\hline & Máxima & 3120 & 3575 & 6270 \\
\hline \multirow{2}{*}{ Esforços } & Mínimo & 25 & 27 & 35 \\
\hline & Máximo & 30 & 32 & 40 \\
\hline \multicolumn{2}{|c|}{$\begin{array}{c}\text { Velocidade em metros por } \\
\text { minuto }\end{array}$} & 520 & 550 & 570 \\
\hline \multirow{2}{*}{$\begin{array}{l}\text { Tempo em } \\
\text { minutos e } \\
\text { segundos }\end{array}$} & Mínimo & 5 e 00 & 5 e 30 & 6 e 00 \\
\hline & Máximo & 6 e 00 & 6 e 30 & 7 e 00 \\
\hline
\end{tabular}

Fonte: FEI. Eventing Rules - 25th edition effective 1st January 2019. 
- prova de salto: onde o conjunto deve realizar um percurso com saltos sobre obstáculos móveis (no nível 2* composto por 10 ou 11 obstáculos à altura de 1,15 metros e largura de 1,35 metros, com um total de 13 esforços. Um mesmo obstáculo pode ter 2 ou 3 esforços, no caso do obstáculo duplo e triplo, respectivamente). As penalidades podem ser o desvio ou refugo (penalizado com 4 PP. O segundo desvio ou refugo no mesmo percurso elimina o conjunto), derrube do obstáculo (penalizado com 4 PP) e ultrapassar o tempo concedido (cada segundo iniciado além do tempo concedido é penalizado com 1 ponto perdido).

Quadro 5 - Prova de Salto: dimensões máximas dos obstáculos, distâncias, velocidades e número de esforços - Anexo C do Regulamento de CCE da FEI - 2019

\begin{tabular}{|c|c|c|c|c|c|}
\hline Parâmetro/ Nível & $\mathbf{1}^{\boldsymbol{*}}$ & $\mathbf{2}^{\boldsymbol{*}}$ & $\mathbf{3}^{\boldsymbol{*}}$ & $\mathbf{4}^{\boldsymbol{*}}$ & $\mathbf{5}^{\boldsymbol{*}}$ \\
\hline Altura em metros & 1.10 & 1.15 & 1.20 & 1.25 & 1.30 \\
\hline Largura do oxer em metros & 1.25 & 1.35 & 1.40 & 1.45 & 1.45 \\
\hline Largura da tríplice em metros & 1.45 & 1.55 & 1.60 & 1.65 & 1.65 \\
\hline Distância em metros & 600 & 600 & 600 & 600 & 600 \\
\hline $\begin{array}{c}\text { Velocidade em metros por minuto } \\
\text { Número de obstáculos/ Número } \\
\text { máximo de esforços }\end{array}$ & 350 & 350 & 350 & 375 & 375 \\
\hline
\end{tabular}

Fonte: FEl. Eventing Rules - 25th edition effective 1st January 2019.

Nas três provas o conjunto é eliminado imediatamente caso o cavalo ou cavaleiro venham a sofrer uma queda.

Será considerado o vencedor da competição o conjunto que obter o menor número de pontos perdidos ao final das 3 provas (FEl, 2019c).

\subsection{Diretrizes para elaboração de uma competição de CCE $2^{*}$}

A CBH no seu Regulamento da modalidade CCE (CBH, 2006), elaborado no ano de 2006 e em vigência até os dias de hoje, no artigo 5.101 do Capítulo I Generalidades define Concurso ou Evento como conjunto da reunião, Espetáculo, Competição, Campeonato etc, organizados sob o controle de uma Comissão Organizadora (CO) designada por uma Federação Estadual. O termo "prova" referese à competição particular na qual os participantes são classificados em função de seus méritos e pelo quais Ihes são atribuídos prêmios. O termo "Comissão Organizadora" refere-se a qualquer Organização, Grupo, Sociedade ou Organismo 
reconhecido por uma Federação Estadual e que tenha a responsabilidade da organização de qualquer evento.

Assim, para a realização de uma competição torna-se necessário que um grupo de pessoas, que ao longo do processo apresenta variações em seu efetivo, planeje, organize e execute o evento. Dependendo da envergadura do evento, este grupo pode ser maior ou ser apenas constituído pelos que são indispensáveis para a competição como comissão de organização, oficiais de concurso, secretaria do evento, pessoal de manutenção indispensável e suporte básico médico e veterinário (CBH, 2017).

Dependendo do nível da competição, nacional ou internacional, os oficiais de concurso devem possuir capacitação em diversos cursos realizados na $\mathrm{CBH}$ e FEI.

Assim, a FEl divide os juízes, delegados técnicos e desenhadores de percurso em dois níveis: 2 e 3 (sendo o nível 3 o com maior capacitação técnica). Os comissários são divididos em três níveis: 1, 2 e 3. Quanto maior a exigência técnica da competição, maior a capacitação técnica exigida do oficial de concurso ( $F E l$, 2019e).

O oficial de concurso pode manter, perder ou elevar o seu nível, dentro de cada função desempenhada. Assim, existem várias normas previstas no Regulamento da $\mathrm{CBH}$ e da $\mathrm{FEl}$, que definem as exigências para que uma pessoa possa desempenhar uma determinada função, em determinado nível, como oficial de concurso: não devem ter mais de 70 anos, devem realizar um número mínimo de eventos por ano e/ ou máximo em uma função específica de oficial de concurso, realizar cursos na FEl com avaliação positiva a cada 3 anos (FEl, 2019c) e devem falar e entender o idioma inglês.

Outra categoria onde os membros não são definidos por níveis, mas por sua função desempenhada durante a competição são os veterinários de competição, que são responsáveis por realizar exames de antidoping nos cavalos, verificar a administração de medicamentos no animal (se são ou não substâncias permitidas pelo regulamento) e verificar as condições de saúde do animal, desde sua chegada ao local da competição, até o término da mesma ( $\mathrm{CBH}, 2018 \mathrm{e})$. Também devem conferir a documentação necessária para a participação de um cavalo em um evento internacional como: Guia de Transporte Animal (GTA), passaporte (documento com vários dados do animal como data de nascimento, nome do proprietário, sinais característicos, altura, filiação e vacinas realizadas. Estes dados permitem a 
identificação do animal) da $\mathrm{CBH}$ e da $\mathrm{FEI}$, selo do passaporte (que deve ser renovado anualmente na $\mathrm{CBH}$ ), vacinas (validade e especificações), exames de mormo - que é uma zoonose ${ }^{2}$ (WHO; FAO, 1951) e de Anemia Infecciosa Equina (AIE) e Atestado de Sanidade Equina. Os veterinários desempenham as seguintes funções em uma competição: delegado veterinário, veterinário de tratamento, veterinário responsável pelo controle sanitário e veterinário de percurso $(\mathrm{CBH}$, 2018e).

Outro ponto a ser destacado na montagem de um quadro de oficiais de concurso para um evento é a preocupação para que não ocorram conflitos de interesses, situação quando uma mesma pessoa é, por exemplo, treinador de um cavaleiro e também juiz da competição que este mesmo cavaleiro está participando. Este fato poderia alterar o julgamento do atleta pelo juiz, uma vez que este também é seu treinador. Desta forma, o regulamento comenta sobre conflitos de interesse que não são desejáveis, mas podem ocorrer, e os que não são permitidos em nenhuma situação (CBH, 2006).

Seguindo o Regulamento de CCE da FEI, as necessidades de oficiais de concurso para uma competição internacional estão elencadas na tabela abaixo:

\footnotetext{
${ }^{2}$ Doenças ou infecções naturalmente transmissíveis entre animais vertebrados e seres humanos.
} 
Quadro 06 - Oficiais de concurso necessários para a montagem de uma competição do formato longo (Concurso Completo Internacional)

\begin{tabular}{|c|c|c|c|c|c|}
\hline Função/ Nível & $\mathbf{1}^{*}$ & $2^{\star}$ & $3^{\star}$ & $4^{\star}$ & $5^{*}$ \\
\hline \multirow{4}{*}{ Júri de Campo } & \multicolumn{3}{|c|}{2 ou 3 júizes } & \multicolumn{2}{|c|}{3 juízes } \\
\hline & \multirow[b]{2}{*}{$\begin{array}{l}\text { Todos podem } \\
\text { ser nacionais }\end{array}$} & \multirow{2}{*}{\multicolumn{2}{|c|}{$\begin{array}{l}\text { Mínimo de } 1 \text { juíz da lista FEI do } \\
\text { Nível } 2 \text { ou } 3\end{array}$}} & \multicolumn{2}{|c|}{ Todos da lista FEI } \\
\hline & & & & $\begin{array}{c}\text { Mínimo de } 1 \\
\text { juíz da lista FEl } \\
\text { do Nível } 3\end{array}$ & $\begin{array}{c}\text { Todos os juízes } \\
\text { da lista FEl do } \\
\text { Nível } 3\end{array}$ \\
\hline & $\begin{array}{l}\text { lista FEI do } \\
\text { Nível } 2 \text { ou } 3\end{array}$ & - & $\begin{array}{l}\text { Obrigatório que } \\
\text { um membro do } \\
\text { JC, DT ou DP } \\
\text { seja estrangeiro }\end{array}$ & \multicolumn{2}{|c|}{$\begin{array}{l}\text { Obrigatório que um membro do } \\
\qquad \mathrm{JC} \text { seja estrangeiro }\end{array}$} \\
\hline Delegado Técnico & \multicolumn{3}{|c|}{ Da lista FEI do nível 2 ou 3} & \multicolumn{2}{|c|}{$\begin{array}{l}\text { TD deve ser da lista FEI do Nível } \\
\qquad 3\end{array}$} \\
\hline $\begin{array}{l}\text { Desenhador de } \\
\text { Percurso }\end{array}$ & \multicolumn{2}{|c|}{ Pode ser nacional } & $\begin{array}{l}\text { Deve ser da } \\
\text { lista FEI }\end{array}$ & \multicolumn{2}{|c|}{ Deve ser da lista FEI do Nível 3} \\
\hline $\begin{array}{l}\text { Desenhador do } \\
\text { Percurso de Salto }\end{array}$ & \multicolumn{3}{|c|}{ Recomendado que seja da lista nacional } & $\begin{array}{l}\text { Tem que ser da } \\
\text { lista nacional }\end{array}$ & $\begin{array}{l}\text { Tem que ser da } \\
\text { lista FEl do } \\
\text { nível } 3 \text { ou } 4\end{array}$ \\
\hline $\begin{array}{l}\text { Delegado } \\
\text { Veterinário }\end{array}$ & \multicolumn{5}{|c|}{ Tem que ser da lista FEI de veterinários de tratamento } \\
\hline $\begin{array}{c}\text { Serviço de } \\
\text { Gerenciamento } \\
\text { Veterinário }\end{array}$ & \multicolumn{5}{|c|}{$\begin{array}{l}\text { Veterinário(s) de tratamento(s), veterinário responsável pelo controle sanitário e } \\
\qquad \text { veterinário(s) de percurso(s) }\end{array}$} \\
\hline Comitê de apelação & \multicolumn{5}{|c|}{ Pode ser composto por 3 pessoas ou 1 pessoa } \\
\hline $\begin{array}{l}\text { Chefe dos } \\
\text { comissários }\end{array}$ & \multicolumn{3}{|c|}{ Da lista FEl do nível 1, 2 ou 3} & \multicolumn{2}{|c|}{ Da lista FEl do nível 2 ou 3} \\
\hline
\end{tabular}

Legendas: DP - Desenhador de Percurso/ DT - Delegado Técnico/ FEI - Federação

Equestre Internacional/ JC - Júri de Campo

Fonte: FEI. Eventing Rules - 25th edition effective 1st January 2019. 


\section{MATERIAL E MÉTODOS}

A abordagem metodológica utilizada nesta pesquisa foi de natureza qualitativa e caracteriza-se como exploratória (YIN, 2006), quanto aos seus objetivos, e descritiva, quanto aos procedimentos.

A pesquisa exploratória explicitou o problema a ser estudado que, neste caso, foi detalhar as diversas ações necessárias para a organização de uma competição internacional de Concurso Completo de Equitação (CCE) no nível 2*.

Foi utilizado para sua elaboração, dados primários, conhecimento tácito do pesquisador (uma vez que o mesmo também tem formação de oficial de concurso) e dados secundários de diretrizes organizacionais disponibilizados pela FEI.

Os procedimentos metodológicos para a realização da pesquisa podem ser sintetizados na Figura 7.

Figura 1 - Sequência das atividades de pesquisa
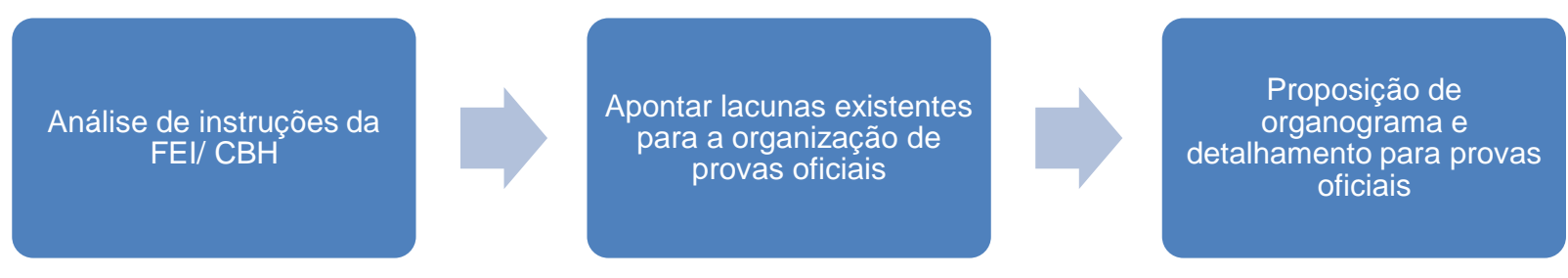

Fonte: Própria autoria.

A seguir são detalhadas algumas das atividades deitas em cada uma das fases:

- Análise de instruções da $\mathrm{CBH}$ e FEl, a partir da consulta dos regulamentos da FEl: Geral, de CCE, orientações para desenhadores de percurso, informações médicas e de segurança e Memorando de orientações de CCE, e da CBH: Geral, de Adestramento, de CCE, de Salto, Veterinário, Estatuto da $\mathrm{CBH}$, Caderno de Encargos e Manual dos Comissários e da United States Eventing Association (USEA) as orientações para obstáculos de cross-country. Assim foram levantadas as principais orientações contidas nos documentos oficiais para a elaboração de competições; 
- Lacunas existentes para a organização de provas oficiais: a partir da análise da documentação supracitada, identificaram-se lacunas de conhecimento e orientações para a estruturação das provas. Esta fase foi de extrema importância, sobretudo, por considerar o conhecimento tácito do pesquisador na vivência de organizações de provas de CCE; e

- Proposição de Organograma e detalhamento para provas oficiais: considerando-se as etapas anteriores, as informações foram ordenadas e estruturadas no organograma que será demonstrado posteriormente. 


\section{RESULTADOS E DISCUSSÃO}

\subsection{Estruturação de organograma para a realização de competições internacionais de CCE $2^{*}$}

A fim de facilitar o entendimento acerca do processo realizado para a solicitação, planejamento e realização de um evento foram apresentados a seguir, as atividades que devem ser realizadas para a preparação e execução de uma competição de CCE, bem como a interpretação de um programa de competição e a movimentação econômica da modalidade CCE.

A maioria dos eventos é realizada no interior de São Paulo, principalmente nas cidades de: Colina, Jaboticabal, Pirassununga e Ribeirão Preto. Além de São Paulo, também são realizadas competições na cidade do Rio de Janeiro - Rio de Janeiro e Brasília - Distrito Federal. Os eventos são realizados em propriedades, hípicas e organizações militares (CBH, 2019b).

Nos últimos anos, o número de eventos nacionais e internacionais no calendário da $\mathrm{CBH}$ tem variado entre 06 e 08 eventos por ano.

Para a realização de provas de CCE, algumas etapas são imprescindíveis. O trabalho se inicia no ano anterior ao da realização da competição, com a solicitação da mesma pela comissão organizadora, à federação estadual que está enquadrada. Após o pedido, esta entidade encaminha a solicitação à $\mathrm{CBH}$.

A comissão organizadora do evento é composta pelas pessoas responsáveis por organizar e realizar o evento e pode ser composta pelo(s) proprietário(s) do local, administrador/ gerente do local (responsável pela manutenção das instalações), gestores esportivos (adotam as medidas administrativas necessárias como confecção de documentação, assessoramento técnico esportivo, autorizações necessárias, buscam prováveis parceiros/ interessados em participar do evento e adotam as ações referentes à preparação das instalações (construção e melhoria de picadeiros de adestramento, pistas de cross-country e salto, cocheiras, estacionamentos, locais de alimentação, alojamentos e banheiros).

Este grupo deve realizar o pedido do evento à federação estadual em que está enquadrado, até o dia 20 de setembro do ano anterior (CBH, 2017) do evento, e esta entidade deve encaminhar a solicitação à Diretoria Técnica da $\mathrm{CBH}$ até o dia 30 de setembro subsequente. Neste documento já são descritas as condições técnicas propostas para a competição como o nível da competição $\left(1,2,3,4\right.$ ou $\left.5^{\star}\right)$, se o 
evento é nacional ou internacional, se é no formato curto ou longo e a data do evento.

Figura 2 - Organograma de solicitação para a realização da competição

\section{Solicitação do da competição pela comissão organizadora}

\section{Federação Estadual}

\section{$\mathrm{CBH}$}

\section{Elaboração}

\section{Equipe indispensável para a competição de $2^{*}$}

Fonte: Própria autoria.

O pedido à $\mathrm{CBH}$ para a realização da competição é primordial, pois neste momento, a comissão organizadora da competição já deve ter verificado se possui condições técnicas (CAVALCANTI, 2011) como:

- área para a montagem dos picadeiros de adestramento;

- percurso de cross-country, com piso de grama e obstáculos fixos para;

- pista(s) de salto;

- cocheiras em número suficiente;

- duchas para banho dos cavalos;

- área de estacionamento para caminhões e veículos leves;

- banheiros para os diversos segmentos participantes do evento;

- áreas de alimentação; e

- instalações elétricas e hidráulicas adequadas para atender todas as demandas advindas das diversas instalações existentes.

Também devem ser levantadas as demandas financeiras como:

- pagamento de taxas à CBH e a FEl para a realização e inclusão do evento nos respectivos calendários; 
- pagamento de diárias e passagens aos oficiais de concurso (dois ou três membros do júri de campo, um delegado técnico, um desenhador de percurso, um chefe dos comissários e três veterinários de competição);

- aquisição de premiação para os melhores classificados de cada nível da competição;

- kit antidoping (para os exames realizados nos animais);

- construção, adequação ou manutenção das instalações onde será a competição; e

- a existência de parceiros/ partes interessadas que possam contribuir de com apoio financeiro, empréstimo de material ou apoio com pessoal especializado para alguma das tarefas existentes (divulgação do evento, montagem de estrutura de alimentação e venda de produtos diversos e som) na competição.

Atualmente, a comissão organizadora normalmente destina pouca atenção a este importante momento do planejamento. Como resultado, muitas vezes estes eventos não geram lucro (ou geram até mesmo prejuízos) e em algumas situações ocorre o seu cancelamento ou alteração das características da competição (ações que levam a aplicação de multas pela $\mathrm{CBH}$ e/ ou FEI). Estes fatos dificultam o desenvolvimento do esporte no país, pois, não permitem o planejamento adequado para a competição, principalmente por parte dos atletas (que não tem dados suficientes para o planejamento dos ciclos de treinamento de seus animais, não possuem condições de realizar um levantamento preciso de custos para a realização das competições com a adequada antecedência e também de elencar as competições mais importantes no ano para si) e de possíveis partes interessadas (que diante das diversas incertezas do planejamento preferem investir em outras modalidades que possuem melhor organização). A existência de empresas especializadas na realização de competições equestres minimizaria estes problemas (PAYNE, 2006).

Após receber a solicitação da federação a que pertence a respectiva comissão organizadora, a CBH deve enviar à $\mathrm{FEI}$, até o dia 30 de outubro do ano anterior, a proposta com as provas internacionais que pretende realizar no ano subsequente no Brasil. Inicialmente a $\mathrm{CBH}$ (em âmbito nacional) e posteriormente a FEI devem verificar se existe algum conflito no calendário (principalmente se existem competições importantes e em locais próximos na mesma data). A concorrência 
entre locais de competição poderia dividir os cavaleiros e com isso enfraquecer ambos os eventos (CBH, 2017).

Verifica-se no Brasil, grande dificuldade de comunicação entre a $\mathrm{CBH}$, federações (particularmente a Paulista) e associações (principalmente a ABHIR), culminando muitas vezes na sobreposição de eventos e grande períodos sem que ocorra nenhum evento, não proporcionando assim, uma distribuição harmônica das datas, o que prejudica o treinamento e condicionamento físico do cavalo para as competições selecionadas pelo cavaleiro como importantes.

Para a realização de competições internacionais chanceladas pela $\mathrm{CBH}$ é cobrada por esta, uma taxa de 1.927 reais $(\mathrm{CBH}, 2018 \mathrm{a})$. Caso o evento também seja da FEI serão cobradas taxas para que seja autorizada a realização do mesmo e para a inclusão do evento no calendário anual. Estas cobranças são calculadas pela FEI e são bastante onerosas. Variam de acordo com o número de competições realizadas e o seu nível técnico. É difícil o acesso a esta informação, antes que a competição seja incluída no calendário da $\mathrm{FEl}$, tornando assim, menos transparente a relação entre a organização e a $\mathrm{FEl}$, sendo que normalmente o valor de cobrança destas taxas é informada durante ou posteriormente a realização do evento propriamente dito. A cobrança destas taxas dificulta a realização de competições por elevar o seu custo fixo além de não trazer benefícios diretos para a competição (como envio de premiação, disponibilização de oficiais de concurso ou apoio com material utilizado nas estruturas das três provas).

A divulgação do calendário da FEl é realizada no dia $1^{\circ}$ de janeiro com as competições aprovadas para aquele ano. A partir da divulgação do calendário, qualquer modificação no formato da competição e/ ou cancelamento da competição acarretará em multa imposta pela FEl e/ ou CBH (este valor é calculado em função do nível e do status da competição. O valor para o cancelamento é de $\mathrm{R} \$ 2.000,00$ e para alteração de data é de $R \$ 1.500,00)$.

Após a aprovação do evento pela FEl, a comissão organizadora inicia ou intensifica as atividades referentes à montagem do quadro de oficiais de concurso necessários para o evento (CAVALCANTI, 2017).

O programa da competição - documento que contem todos os dados relativos à realização da competição (horários, locais, taxas a serem pagas pelos competidores, nome dos responsáveis pelas diversas atividades e facilidades oferecidas pela organização) e que é confeccionado pela comissão organizadora, 
deve ser enviado com antecedência de pelo menos 30 dias da competição para a aprovação da $\mathrm{CBH}$ e, caso a competição seja internacional, o mesmo também será encaminhado pela $\mathrm{CBH}$ à $\mathrm{FEI}$, para a sua aprovação e deverá conter também, a versão na língua inglesa ( $\mathrm{FEl}, 2019 \mathrm{~b})$.

A CBH e, posteriormente, a FEl verificam se todas as exigências técnicas e administrativas previstas em seus diversos regulamentos estão sendo atendidas. Assim são verificadas se as reprises propostas para o adestramento (Quadro 1), as dimensões dos obstáculos (altura, largura e características - Quadros 2 e 5), as distâncias dos percursos do cross-country e salto (Quadros 3, 4 e 5), as exigências solicitadas para cada função como juízes, delegado técnico, desenhador de percurso, veterinários de competição e chefe dos comissários e também, as taxas cobradas (valor de inscrição e de aluguel de baias) estão dentro dos parâmetros estabelecidos em diversos regulamentos e se são adequados ao nível da competição.

Para cada nível e formato de competição, os oficiais de concurso necessitam de uma capacitação específica. Assim, quanto maior o nível de dificuldade e complexidade do evento, maiores serão as exigências técnicas para a montagem do quadro de oficiais (FEl, 2019e).

Os oficiais de concurso devem realizar e obter aproveitamento em diversos cursos, antes de serem incluídos como oficiais de concurso na Lista FEl. Obrigatoriamente, a formação de todos os oficias de concurso (júri de campo, delegado técnico, desenhador de percurso, comissários e veterinários de concurso) inicia-se na $\mathrm{CBH}$, com um curso (dentro de cada função supracitada) com duração aproximada de quatro dias cada. Este curso é ministrado por um instrutor habilitado pela $\mathrm{CBH}$. Caso aprovado, o interessado deve realizar outros cursos de capacitação na FEl, ministrados por pessoal da FEl. Não é clara a sequência de cursos a serem realizados, bem como a o oferecimento destes não é constante e devidamente divulgado (FEl, 2019a).

Para a capacitação das funções, a FEI normalmente realiza um curso para as funções de comissários e veterinários de competição e dois cursos (Nível 1 e 2) para as funções júri de campo, delegado técnico e desenhador de percurso, cada um destes cursos também tem duração de quatro dias, e podem ser realizados no Brasil ou em outro país. Caso obtenha aproveitamento mínimo, o candidato será submetido a uma avaliação da FEI e, se aprovado, será incluído no quadro da FEI 
de oficial de concurso de sua respectiva função. Cada curso deste tem um valor entre 100 e 150 dólares (entre 400 e 600 reais em valores atuais).

Verifica-se em nosso país a falta de cursos para formação de oficiais de concurso, tanto da CBH como da FEI. A realização dos Jogos Olímpicos RIO 2016 não impulsionou o aumento de oficiais de concurso de CCE no Brasil perdendo-se assim uma oportunidade ímpar para o desenvolvimento deste importante setor das competições.

O reduzido número de algum tipo específico de oficial de concurso (júri de campo, delegado técnico, desenhador de percurso, comissários e veterinários de concurso) impacta significativamente e de forma negativa a realização das competições no Brasil, pois há a necessidade de convidar um oficial de outro país encarecendo custos do evento e dificultando a logística de organização da competição (CBH 2019c).

O desenvolvimento técnico dos cavaleiros também não é estimulado uma vez que estes já conhecem o julgamento na prova de adestramento dos juízes, as tendências na montagem dos obstáculos pelo desenhador de percurso e presumem os detalhes que receberão maior e menor atenção por parte do delegado técnico.

A carência de oficiais de concurso ocorre em toda a América Latina, diferentemente de países como a Grã-Bretanha, Alemanha, França, Nova Zelândia, Austrália e Estados Unidos, que possuem elevado número de oficiais de concurso em todas as funções - júri de campo, delegado técnico, desenhador de percurso, comissários e veterinários de concurso - facilitando assim, o desenvolvimento do esporte (FEl, 2019d).

Uma vez aprovada a realização da competição, outro passo para a organização se inicia. Neste momento várias frentes de trabalho são formadas para atender a demanda das quatro principais áreas para a realização da competição, todas elas com seus respectivos oficiais de concurso inseridos (Figura 3). 
Figura 3 - Organograma de hierarquia dos grupos envolvidos para a realização da competição

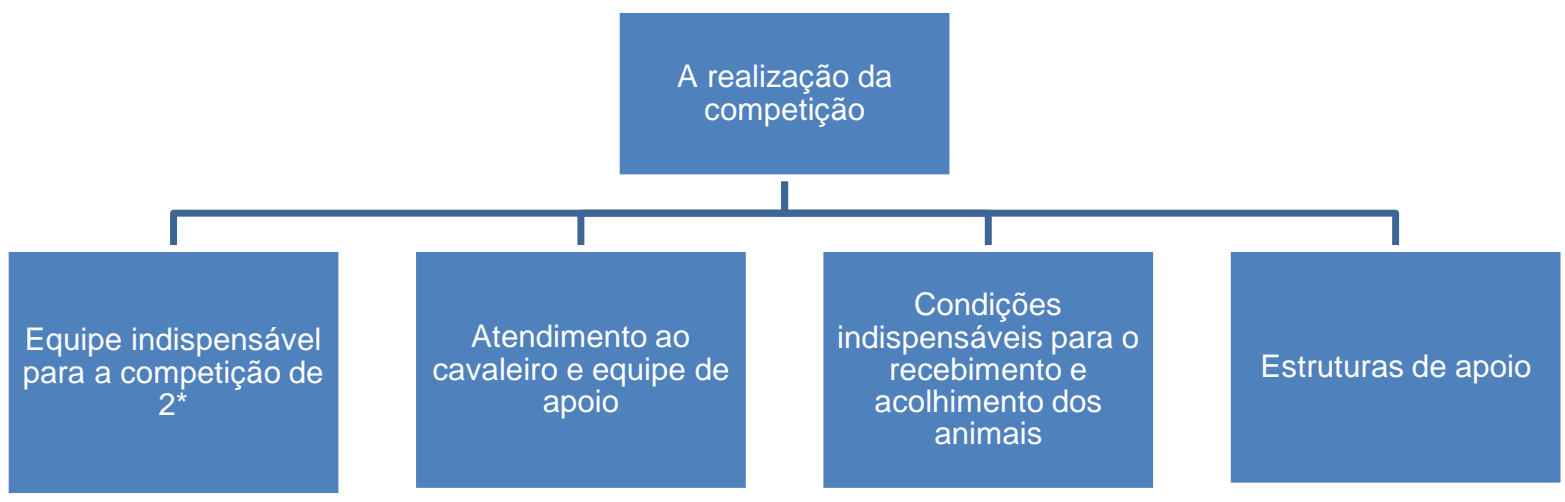

Fonte: Própria autoria.

A equipe indispensável para a realização de uma competição de $2^{*}$ é composta pela comissão organizadora e pelos oficiais de concurso exigidos no regulamento para garantir a área administrativa, a de segurança e de bem estar do cavalo e do cavaleiro. Cada um destes tem uma função específica e vinculada descrita a seguir.

Na figura 4 - Hierarquia dos oficiais de concurso.

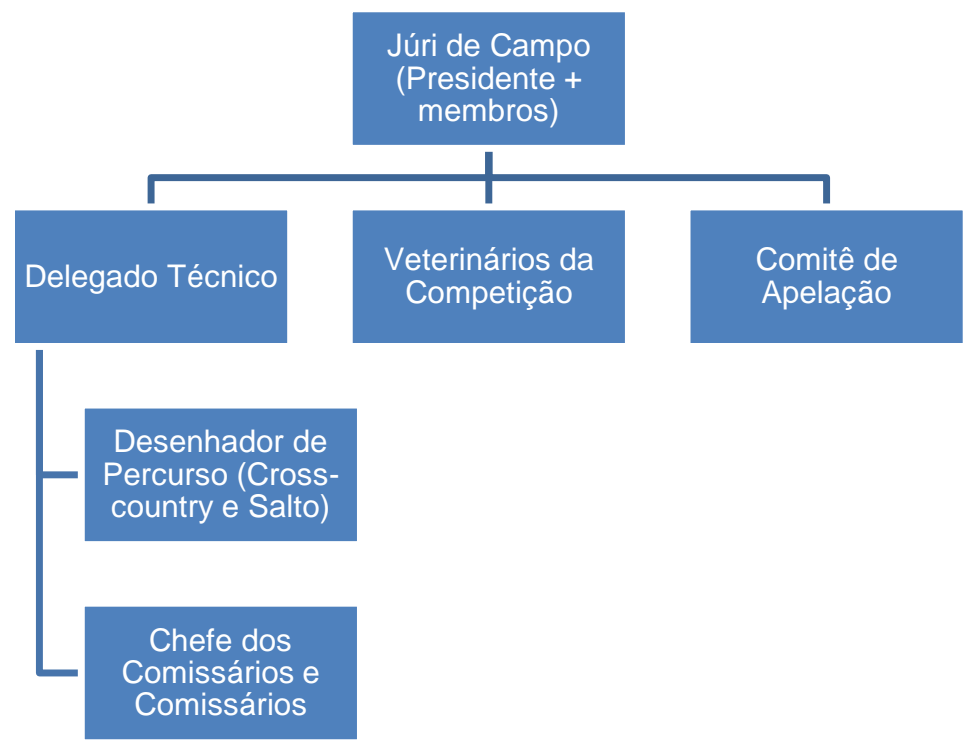

Fonte: Própria autoria.

O júri de campo é a autoridade máxima da competição, subordinados a ele estão o delegado veterinário, os veterinários de competição e o comitê de apelação, os quais têm trabalhos específicos, e assessoram em conjunto, o júri de campo. São 
assessores do delegado técnico, os desenhadores de percurso (cross-country e salto - se houver, não é obrigatório) e os comissários.

O júri de campo é composto por um presidente do júri e mais um ou dois membros, sendo que pelo menos um destes juízes devem constar da lista FEl. Caso nenhum dos integrantes do júri de campo seja estrangeiro, o delegado técnico ou o desenhador de percurso deve ser de país estrangeiro (FEI, 2019c).

Os membros do júri de campo são responsáveis pelo julgamento de todo evento e da resolução de problemas que possam surgir durante a competição. Em conjunto com o delegado técnico, desenhador de percurso e comissão organizadora devem assegurar que todas as providências para o concurso ocorram dentro das normas previstas no regulamento Geral e de CCE da FEI. Devem participar juntamente com o delegado veterinário da primeira e da segunda inspeção dos cavalos (quando houver), momento em que, o cavalo conduzido por seu cavaleiro (a pé), é puxado ao passo e ao trote e é observado se o mesmo está em condições físicas adequadas para ser montado e competir, sem comprometer o bem-estar animal $(\mathrm{CBH}, 2018 \mathrm{e})$.

$\mathrm{Na}$ prova de adestramento atribuem notas ao conjunto, onde podem ser auxiliados pelo juiz de arreamento (que tem a atribuição de verificar se o material utilizado pelo conjunto está de acordo com o Regulamento de Adestramento da FEI $(\mathrm{CBH}, 2018 \mathrm{c}))$. Realizam também o julgamento da prova de salto onde também podem ser auxiliados por um juíz da modalidade salto, anotadores de resultados, cronômetristas, juízes de obstáculo (para verificar se as dimensões dos obstáculos saltados estão dentro dos parâmetros previstos no Regulamento) na distensão (fase de aquecimento) e na pista e pistinhas - que recompõe os obstáculos em posição quando estes são modificados pelo conjunto durante a execução do seu percurso, recuperam o piso da pista e mantem a ornamentação da pista $(\mathrm{CBH}, 2018 \mathrm{~d})$.

Qualquer membro do Júri tem o dever e total autoridade durante todo o concurso para eliminar qualquer cavalo claudicando, doente ou exausto e os cavaleiros sem preparo físico - não haverá apelação para contra esta decisão $(\mathrm{CBH}$, 2006). A jurisdição do júri de campo se inicia uma hora antes da primeira inspeção dos cavalos (ou do início da prova de adestramento, caso não seja realizada a primeira inspeção dos cavalos e se encerra uma hora após a divulgação dos resultados oficiais). 
O delegado técnico aprova todas as demandas técnicas (dimensões dos obstáculos na prova de cross-country e salto, estado do piso do local das três provas e suas respectivas áreas de treinamento, verificação do quadro horário das três provas (em consonância com a secretaria do evento)) e administrativas (condições dos alojamentos dos cavaleiros e tratadores, estacionamentos (carros e caminhões), cocheiras, suporte e funcionamento da rede hidráulica e elétrica, locais de alimentação) e verifica o estado dos diversos materiais utilizados (obstáculos, letras do picadeiro, casinhas dos juízes do adestramento, sino, sistema de som, qualidade do piso, iluminação e controle de acessos) na inspeção dos cavalos, áreas de treinamento e nos locais das provas de adestramento, cross-country e salto de um evento (FEl, 2018b).

É auxiliado no controle e acompanhamento durante o evento pelos comissários (que são coordenados pelo chefe dos comissários) e deve auxiliar o júri de campo supervisionando o desenrolar técnico da competição e tomando as medidas necessárias, sempre com aprovação do júri de campo.

O delegado técnico deve visitar previamente o local da competição a fim de se familiarizar com o ambiente e sugerir a preparação adequada do local (entretanto isto está condicionado à disponibilidade de recursos da comissão organizadora) e deve chegar pelo menos um dia antes da chegada dos primeiros cavalos e cavaleiros para verificar as condições técnicas e administrativas do local da competição, sendo responsável por mantê-las até o término do mesmo. Supervisiona as instruções e conduta de todos os comissários para que estes exijam dos cavaleiros e tratadores, o fiel cumprimento das normas. Além disso, deve verificar antes do início da competição se o cavaleiro e o cavalo estão qualificados (se já participaram com aproveitamento em outras competições que o habilitem a participar da competição em questão) e se possuem alguma suspensão ou punição por doping ou cartões amarelos recebidos por equitação perigosa e/ ou abuso de cavalo (FEl, 2019c). Verifica todos os resultados após a apuração dos mesmos pela secretaria do evento, a fim de verificar se foram corretamente apurados. Deve enviar um Relatório à $\mathrm{FEl}$, até dois dias após o término do evento, sobre a maneira como a competição ocorreu (FEl, 2019g). Deve compor a lista FEl, do nível 2 ou 3.

$O$ desenhador de percurso é o encarregado pelo planejamento, definição e medição dos percursos. Idealiza e com o auxilio de uma equipe constrói os obstáculos de cross-country e salto. Para o $\mathrm{CCl} 2^{*}$ o desenhador de percurso pode 
ser nacional. Pode ser designado um desenhador de percurso nacional somente para a prova de salto, entretanto, pelo Regulamento de CCE da FEI (2019c), isto não é obrigatório, somente recomendado. Após a preparação do percurso (montagem dos obstáculos e preparação do piso), o desenhador de percurso deve mostrá-lo ao delegado técnico, que verificará se as condições técnicas como dimensões dos obstáculos, dispositivos de segurança, e extensão do percurso estão de acordo com os parâmetros estabelecidos pelo Regulamento de CCE da FEI.

O delegado técnico tem autonomia de alterar apenas os obstáculos que não atendam as normas de segurança do Regulamento de CCE da FEI. Após a aprovação do percurso pelo delegado técnico, os dois percorrem o mesmo com o júri de campo. Nesta verificação, o júri de campo pode fazer alterações se julgar necessárias, desde que seja por motivo de segurança ou para adequação do nível da competição ( $\mathrm{FEl}, 2018 \mathrm{~b})$.

Os veterinários da competição são responsáveis pela aprovação de todas as medidas veterinárias do concurso. São divididos nas funções de delegado veterinário, veterinário de tratamento, veterinário responsável pelo controle sanitário e veterinário de percurso.

O delegado veterinário é responsável por assegurar que todas as normas veterinárias serão mantidas e cumpridas durante o concurso e deve ser integrante da Lista FEl. Deve trabalhar em conjunto com os membros do júri de campo a fim de assessorá-los nas decisões que envolvam qualquer questão sobre a área veterinária durante a competição. Deve ser notificado pelo veterinário de tratamento sobre qualquer tratamento veterinário realizado (aplicação de medicamentos diversos) em um animal que esteja participando da competição. Supervisiona as atividades para o recebimento de kits antidoping dos cavalos e a realização do exame propriamente dito (que é realizado por um veterinário de tratamento). Participa das inspeções dos cavalos juntamente com os integrantes do Júri de Campo (CBH, 2018e).

$\mathrm{O}(\mathrm{s})$ veterinário(s) de tratamento(s) indicado(s) para a competição deve $(\mathrm{m})$ constar da Lista FEI. Para o $\mathrm{CCl} 2^{*}$, existe a obrigatoriedade de somente um veterinário de tratamento, entretanto, caso a comissão organizadora julgue pertinente podem ser utilizados mais veterinários de tratamento. Deve realizar o exame veterinário no momento da chegada do animal ao local de competição verificando as condições físico-sanitárias e realizando o exame sumário da documentação, que será posteriormente encaminhada para o veterinário 
responsável pelo controle sanitário ( $\mathrm{CBH}, 2018 \mathrm{e})$. Durante a inspeção dos cavalos permanece no Holding Box, local para onde são encaminhados os cavalos que, após a apresentação inicial pelo cavaleiro ao passo e ao trote, a aptidão seja duvidosa para participar do evento (por motivo de claudicação, estado de saúde ou outro tipo de ferimento/ lesão). Durante a realização da prova de cross-country deve permanecer no local da chegada para examinar as condições do cavalo na chegada verificando se está exausto ou sofreu alguma lesão e por isso, necessita de algum tratamento imediato. Os cavalos após a sua chegada são liberados para a baia somente após receberem a autorização do veterinário de tratamento ( $F E I, 2018 b)$.

Quando houver a necessidade ou uma solicitação para a aplicação de medicamentos controlados nos cavalos, este deve fornecer os formulários aos interessados e posteriormente encaminhá-los ao delegado veterinário para a sua aprovação, antes da administração dos medicamentos.

O veterinário de percurso não é obrigatório para um $\mathrm{CCl} 2^{*}$, entretanto quando houver, deve ser da Lista FEI e será encarregado de supervisionar uma grande área como o cross-country (ou parte dele) e deve estar em condições de realizar atendimentos veterinários de emergência em sua área durante a prova. Também mantem contato com os demais veterinários transmitindo informações sobre os cavalos que tenham sofrido alguma lesão ou que possam estar exausto (não tem autoridade para eliminar um cavalo que julgue estar com manqueira e/ ou exausto, mas deve informar o mais rápido possível ao júri de campo sobre o fato observado).

O veterinário responsável pelo controle sanitário recebe e verifica toda a documentação dos animais como exames de AIE e mormo, atestado de sanidade, Guia de Transporte Animal (GTA), passaportes e verifica a chipagem (pequeno dispositivo de transmissão passiva, subcutâneo e instalado no terço anterior do pescoço do animal). Deve fazer parte da lista FEI como veterinários de tratamento (CBH, 2018e).

Um ponto importante é que nenhum veterinário da competição pode eliminar um concorrente por motivo de claudicação, lesão ou ferimento, entretanto deve comunicar o mais rápido possível qualquer fato observado neste sentido, a um dos membros do júri de campo, que tem autonomia para eliminar o conjunto (FEl, 2019c). 
Ainda compondo a equipe indispensável para a realização da competição, a secretaria do evento recebe as inscrições e pagamentos dos conjuntos, os pedido de baias e alojamentos para cavaleiros e equipe de apoio dos mesmos (tratadores e motoristas), realiza esclarecimentos sobre os locais de alimentação, rede hoteleira e os meios de transporte. Fornece também, em coordenação direta com o delegado técnico, a documentação referente à competição como: reprises de adestramento (previstas no programa da competição) para cavaleiros e juízes, numeração para cavalos e cavaleiros, quadro-horários e divulgação de resultados.

Também deve ser constituído um comitê de apelação (com seu(s) membro(s) já designado(s) no programa da competição), com integrante(s) que conheça(m) os regulamentos de CCE e Veterinário da FEl. Este comitê tem a atribuição de quando solicitado pelo júri de campo, auxiliar em decisões sobre a participação do conjunto (causas de eliminação, desqualificação e julgamento de uma das três provas) em que se torne duvidosa a interpretação de algum artigo do regulamento. Pode ser composto por um ou três membros. Esta quantidade de integrantes tem o objetivo de evitar empates caso seja necessário resolver algum assunto por votação do comitê (CBH, 2017).

O ferrador da competição é o responsável por atender cavalos que tenham perdido ou tenham necessidade de ajustar a ferradura durante toda a competição. Os competidores podem se utilizar de outros profissionais, caso desejem.

A equipe médica e a ambulância devem estar disponíveis para o atendimento dos cavaleiros, tratadores ou oficiais de concurso que tenham se acidentado na competição. Deve estar em condições e em contato com pelo menos um hospital em condições a fim de atender acidentes advindos de quedas, que podem levar a fraturas, torções e concussões (FEl, 2019f).

Os comissários podem atuar em diversos locais da competição como cocheiras, pistas de treinamento e das provas de cross-country e salto são coordenados pelo chefe dos comissários (este trabalha em estreita ligação com o delegado técnico). Esta equipe é responsável por acompanhar as atividades ligadas ao treinamento dos cavalos tanto nas cocheiras como nas pistas de prova ou aquecimento, evitando o abuso do cavalo (Art 526 do Regulamento de CCE da FEI), seja pelo cavaleiro, tratador, proprietário ou qualquer outra pessoa. Tem o dever de evitar infração aos princípios de conduta, manter a lealdade e as normas de espírito esportivo (CBH, 2018b). Devem evitar qualquer forma de prática ilegal que possa 
comprometer o bem-estar do cavalo e/ ou integridade da competição. O chefe dos comissários deve ao final do concurso encaminhar ao delegado técnico um relatório com informações sobre como transcorreu a competição. Este relatório posteriormente será encaminhado à $\mathrm{FEl}$. O chefe dos comissários deve constar da lista FEl e pode ser do Nível 1, 2 ou 3.

\subsection{Necessidades para a realização da competição e suas características}

5.2.1 Descrição das condições indispensáveis para o recebimento e acolhimento dos animais

Para a realização das competições, estruturas como cocheiras, embarcadouro, alojamento de tratadores, duchas, veterinária e ferradoria são essenciais.

As informações de tamanho das baias, disponibilidade ou não de cama para os animais, existência de alojamento para tratadores devem constar do programa do evento (FEl, 2019b). Muitas vezes, estas informações são omitidas em eventos que não ocorrem sob a chancela da $\mathrm{FEl}$, fato que dificulta o planejamento para a participação da competição, por parte dos cavaleiros e desta forma acaba comprometendo o bem estar dos animais, cavaleiros e de sua equipe de apoio (tratador, motorista e auxiliares).

A área de desembarque do animal (desembarcador) é o local onde ocorre o embarque/ desembarque do animal. Muitas vezes não é encontrada nos locais de competição sendo o embarque/ desembarque realizado somente com a rampa do caminhão fato que dificulta o procedimento e pode ocasionar acidentes com 0 animal. Este local deve ser preferencialmente afastado das pistas, estacionamentos e locais de aglomeração, a fim de que o cavalo durante o embarque/ desembarque não sofra estímulos indesejáveis, fato que pode deixa-lo agitado, ocasionando algum tipo de ferimento por causa de sua movimentação (coices, movimentação dos membros e quedas). Esta instalação também deve possuir iluminação, uma vez que muitas vezes os desembarques ocorrem durante o período da noite.

A área de estacionamento dos caminhões deve ser preferencialmente uma área ampla, ventilada, com piso firme e bom escoamento, que possua pontos de energia elétrica e fornecimento de água e se possível com locais de sombra próximo. Esta estrutura permite que além dos caminhões, fiquem pernoitando neste local, tratadores, cavaleiros e até proprietários, com a estrutura de apoio adequada 
existente em seus próprios caminhões (com banheiros, dormitórios, cozinhas, entre outras estruturas). Esta estrutura de apoio no Brasil, na maioria dos locais de competição, ainda é extremamente precária, não proporcionando assim as melhores condições aos participantes do evento, como pode ser observado, por exemplo, em competições na Europa, local de referência da modalidade (CAVALCANTI, 2017).

O alojamento para o tratador não é obrigatório e quando existente deve ser próximo ao alojamento dos cavalos. Deve possuir camas, sanitários com duchas, ser bem arejado, oferecer rede wi-fi e local para alimentação próximo. Muitas vezes esta instalação não recebe a atenção adequada por parte da comissão organizadora e assim, não proporciona ao tratador, que tem uma função primordial para a realização do evento (auxilia no transporte e nos cuidados diversos com os animais permitindo que este esteja nas melhores condições para a realização de toda a competição) uma estrutura confortável e adequada.

O local de movimentação e de treinamento dos animais deve estar disponível para o treinamento dos cavalos para as três provas: adestramento (com picadeiros montados com as dimensões oficiais), cross-country (obstáculos fixos montados sobre piso de grama e se possível, um pista para galope) e salto (obstáculos móveis montados sobre piso de areia).

$\mathrm{Na}$ área veterinária serão realizados os atendimentos dos animais, exceção feita ás emergências, que normalmente serão atendidas no local do ocorrido e preferencialmente com a ambulância veterinária (caso o animal que tenha se machucado não tenha condições de deslocar-se até a área veterinária). Também é o local onde o veterinário da competição, responsável por receber a documentação, reúne a mesma e realiza os despachos necessários.

5.2.2 Atendimento ao cavaleiro, oficiais de concurso, comissão organizadora, equipe de apoio e demais participantes

Estas estruturas embora não sejam indispensáveis para a realização da competição são importantes para o bem estar dos envolvidos no evento e podem impactar significativamente a qualidade do mesmo. Atualmente existe uma grande tendência para que a maioria destas estruturas seja móvel e não permanente reduzindo assim os custos de manutenção decorrentes do período que não são utilizados após o evento (POIT, 2013). 
Os banheiros e vestiários são necessários para cavaleiros, tratadores e motoristas. Estas estruturas (permanentes ou temporárias) são muito importantes para aqueles que permanecem no local da competição, seja em alojamentos, nos caminhões ou até mesmo em barracas. Por isso devem ser alvo da atenção da organização, pois devem ser em número suficiente, em locais adequados, possuir chuveiros, iluminação e se manterem em condições de limpeza durante o desenrolar de todo o evento.

Os locais de alimentação são importantes para o oferecimento de alternativas de alimentação (de acordo com o poder aquisitivo e perfil dos clientes) durante a competição, evitando que as pessoas envolvidas na competição, até mesmo o público em geral, necessite sair do local do evento para alimentar-se. Muitas vezes 0 local que abriga a competição não é próximo às cidades, fato que dificulta a busca de opções para alimentação por parte da assistência e outras partes envolvidas (OLYMPIC SOLIDARITY, 2007).

Os meios de transporte existentes são um ponto importante para 0 desenvolvimento da competição. Como no Brasil a maioria dos eventos ocorre em propriedades no meio rural, a comissão organizadora deve levantar quais são os meios de transporte existentes e se existe a possibilidade de que sejam criados meios temporários para atender aos diversos deslocamentos necessários entre o aeroporto, os locais de hospedagem, os locais de alimentação, o comércio e o local de competição.

\subsubsection{Estruturas de apoio}

Estas estruturas normalmente são de natureza temporária. Podem ser montadas sob a coordenação da comissão organizadora ou pelos próprios interessados. É importante que sejam posicionados em locais que facilitem o seu acesso permitindo desta maneira, as melhores condições para atingir o fim a que se destinam.

A arquibancada (permanente ou temporária) raramente existente nos eventos em nosso país dificulta o acompanhamento da competição pelo público.

Estruturas de venda de produtos relacionados a equinos (alimentação, suplementos veterinários, ferrageamento, produtos de manejo, selaria e vestuário) são interessantes, pois, grande parte dos cavaleiros realiza compras em locais de 
competição, uma vez que normalmente não existem lojas especializadas no local onde moram e treinam.

Os banheiros também devem existir em quantidade suficiente para atender o público, devem ser posicionados em locais adequados e próximos aos locais de maior acesso (contudo, não devem comprometer a parte técnica da realização da competição) e devem estar em excelentes condições de limpeza durante todo o evento.

Os locais de alimentação podem ser compartilhados entre os diversos segmentos (público, proprietários de animais, cavaleiros, oficiais de concurso e equipe de apoio) ou podem ser separados a fim de criar um atendimento mais personalizado para cada segmento, seja no que tange aos itens do cardápio, seus respectivos valores de cobrança, aos horários de funcionamento e aos serviços prestados.

\subsection{Estruturação de potencial de negócio e a atratividade do segmento equestre para $\mathrm{o}$ agronegócio cavalo}

A organização das competições é bastante complexa por não ser direcionada apenas ao cavalo e sim ao conjunto (cavalo e cavaleiro) e sua família, equipe de apoio, oficiais de concurso e público em geral. As principais preocupações então na manutenção da segurança do conjunto no decorrer da prova, o bem-estar de todas as pessoas envolvidas e o bem estar animal.

O grupo de oficiais deve trabalhar em sinergismo e por isso cada um deles deve estar devidamente treinado para exercer sua função. $O$ júri de campo deve estar capacitado para resolver qualquer problema que ocorra na competição de forma oportuna e com efetividade.

A formação de oficiais no Brasil é muito difícil e não existe um cronograma de realização de cursos e capacitação dos oficiais, minimizando as alternativas e muitas vezes viciando as competições, uma vez que os competidores já conhecem a forma de julgamento do profissional e as especificidades dos desenhadores de percurso. Nestas condições existe pouco estimulo ao desenvolvimento dos cavaleiros nacionais que podem ser prejudicados em competições internacionais quando se deparam com situações nunca antes enfrentadas.

A falta de empresas especializadas para a organização de eventos de concurso completo de equitação torna cada competição um evento particular, 
esquecendo que este faz parte de um cronograma FEI ou $\mathrm{CBH}$ em que o cavaleiro deverá seguir para qualificar o seu cavalo para os níveis de dificuldade superior. A falta de controle e centralização das informações debilita a transparência dos custos de realização do evento, principalmente no que tange a remuneração dos oficiais de concurso. Este fato não contribui para que mais pessoas se envolvam na montagem das competições, visto o grau de incerteza existente em seu planejamento e execução.

Montar um núcleo de capacitação de oficiais de concurso e estabelecer o prólabore ideal para cada função seria muito importante para aumentar o profissionalismo da atividade, diminuir o empirismo, gerar maior controle das fragilidades do processo e incentivar que as pessoas buscassem continuamente a sua capacitação e desenvolvimento profissional. A maior capacitação de oficiais aumentaria o nível das competições nacionais e o preparo dos conjuntos nacionais para competições internacionais.

A existência de um pró-labore digno e justo poderia atrair maior numero de pessoas e diminuiria a condição de empirismo considerada no agronegócio cavalo (LIMA, SHIROTA e BARROS, 2006).

A gestão do evento realizada por uma empresa poderia favorecer a padronização da qualidade das competições, organizando e distribuindo de forma igualitária os juízes, e principalmente coordenando o balanço econômico da competição. Em posse destas informações seria possível padronizar e ajustar as taxas cobradas pela CBH para a realização das provas.

Como a realização da competição tem característica de um complexo, seria muito importante inserir estas informações no estudo do agronegócio cavalo sistematizadas por Lima e Cintra em 2015 e verificar que a movimentação econômica de uma competição é considerável.

Para que seja possível a participação dos conjuntos (cavaleiros e cavalos) em competições oficiais de CCE é necessário que estes estejam filiados a associações locais como a ABHIR (Associação Brasileira de Hipismo Rural) e associações estaduais que são as federações como a Federação Paulista de Hipismo. Para as competições internacionais (que também ocorrem no Brasil) também é necessário ser membro da Confederação Brasileira de Hipismo, além do registro internacional tanto do cavalo como do cavaleiro. 
Competições não oficiais não apresentam esta exigência o que dificulta ainda mais o controle e mensuração deste negócio.

Para a participação do cavalo e cavaleiro, são cobradas algumas taxas. Considerando os valores das taxas da Confederação Brasileira de Hipismo para o ano de 2019, os documentos a serem adquiridos são: passaporte para o cavalo adquirido uma única vez ( $R \$ 187,00)$, selo para o passaporte - que deve ser adquirido anualmente $(R \$ 771,00)$ totalizando $R \$ 958,00$ de investimento para começar o ano hípico (CBH, 2019a). Além desta taxa, os cavaleiros devem pagar as taxas de anuidade de suas federações. Na Federação paulista de Hipismo (FPH), a taxa de registro do cavaleiro de CCE para o ano de 2019 é de $R \$ 486,00$, acrescido de $R \$ 312,00$ para registro de cada um dos seus cavalos (FPH, 2019). Também deve pagar a anuidade à $\mathrm{CBH}$, atualmente no valor de $\mathrm{R} \$ 88,00$. Inicia-se o ano hípico com investimento de $\mathrm{R} \$ 1844,00$, para um conjunto. Caso o conjunte participe de eventos internacionais necessita ainda ter o ser registro e do cavalo, cada um no valor de $\mathrm{R} \$ 133,00$.

Atualmente a FPH tem 2007 cavalos filiados e 1776 cavaleiros. Utilizando os valores acima informados, a movimentação econômica anual desta federação é de aproximadamente $\mathrm{R} \$ 1.666 .920,00$ no total ${ }^{3}$.

A fim de exemplificar a movimentação econômica de uma competição de CCE, utilizou-se a analise do programa da competição do $18^{\circ}$ Campeonato Internacional Forte Anhanguera, por ter ocorrido na cidade de Pirassununga em 2018 (BRASIL, 2018).

O valor de inscrição na prova para a categoria de 1 estrela (a designação deste nível de competição foi alterado no Regulamento de CCE da FEI de 2019 para "2 estrelas") foi de $R \$ 250,00$ por conjunto. O valor da baia foi de $R \$ 200,00$ por cavalo. O custo dos exames de AIE e de Mormo é de R $\$ 68,00$ (LABORATÓRIO, 2019) além de $R \$ 50,00$ referentes à emissão do GTA (é emitido um para o deslocamento de ida para a competição e outro para o retorno). O cavalo também deve ter um chip identificador no pescoço, que é colocado de forma subcutânea no pescoço do animal por veterinários cadastrados pela $\mathrm{CBH}$ ao valor médio de $\mathrm{R} \$$ 100,00 . O investimento inicial para a participação da prova foi de $R \$ 718,00$.

\footnotetext{
${ }^{3}$ Dado fornecido a Profa. Dra. Roberta Brandi pela FPH em janeiro de 2019.
} 
Além destes valores, investimentos para o deslocamento, alojamento, e cuidados de cavalos e cavaleiros são necessários. Em geral, serão pagas as diárias do motorista do caminhão, tratadores, treinadores e do veterinário da equipe.

Como existe praticamente uma competição por mês (entre competições estaduais, nacionais e internacionais), o cavaleiro vai desembolsar este montante mensalmente, o que implica em grande movimentação econômica, mas sem registro em estudos do agronegócio cavalo, informação que concorda com Lima, Shirota e Barros (2006).

Lima e Cintra (2015) informaram que a rende gerada no Complexo do Agronegócio do Cavalo no Brasil, em abril de 2015, totalizou R $\$ 16,15$ bilhões com 607.329 pessoas ocupadas diretamente, além de 2.429 .316 empregos indiretos totalizando com isso, mais de 3 milhões pessoas ocupadas. Quando se considerou apenas a população de cavalos de esporte e lazer a movimentação econômica é da cifra de 5,84 bilhões de reais. Dentro dos cavalos de esporte o CCE representa 0,9\% das atividades esportivas vinculadas a equinos.

Quando se trata de população de equinos e principalmente de cavalos de competição, o levantamento de dados é dificultado pela forma de obtenção destes. Para o levantamento da população de equinos publicada no estudo, as populações informadas são obtidas por levantamento do IBGE e este é feito em propriedades onde o cavalo coexiste com o bovino ou informada pelas associações.

A realidade do mundo do cavalo é que nem sempre os cavalos estão filiados a alguma associação e os cavalos de esporte do CCE dificilmente estarão em propriedades que também tenham bovinos. Os cavalos estão alocados em centros de treinamento pulverizados nos grandes centros e não avaliados pelo IBGE. Assim, a população informada nos estudos pode estar subestimada não informando precisamente a movimentação econômica gerada pelo cavalo.

Estudos sobre a movimentação econômica do agronegócio cavalo e principalmente sobre a estruturação e movimentação econômica de provas de CCE são escassos e certamente as informações obtidas contribuiriam muito no estudo do complexo do agronegócio cavalo. 


\section{CONCLUSÃO}

Este é um trabalho inédito que sistematizou as orientações dos regulamentos da $\mathrm{FEI}$ e da $\mathrm{CBH}$, gerando informações instrutivas e organizadas que permitem a estruturação das competições internacionais de CCE $2^{*}$, a ação específica e a hierarquização dos oficiais, permitindo a compreensão da organização de uma competição de CCE. É um documento que reúne informações práticas enriquecidas pela vivência do autor.

A movimentação econômica do CCE atinge cifras relevantes e se faz necessário estruturar este potencial de negocio para que ele se torne atrativo para investimentos não só econômicos, mas também na capacitação de profissionais para que as competições de CCE sejam cada vez mais valorizadas, melhor organizadas e que possam atender o maior publico possível, tanto ligado ao cavalo, como também a sociedade que poderá ter acesso a um grande evento. 


\section{REFERÊNCIAS}

ASSOCIAÇÃO BRASILEIRA DE HIPISMO RURAL (ABHIR). Disponível em: < http://www.abhir.com.br/cce>. Acesso em 04 de fevereiro de 2019.

BRASIL. 13ำ REGIMENTO DE CAVALARIA MECANIZADO. Programa do 18을 Concurso Completo de Equitação 2018. Disponível em <http://www.abhir.com.br/images/temp/1197.pdf>. Acesso em 13 fevereiro de 2019.

BRASIL. Ministério da Defesa. Manual Técnico Equitação (EB60-ME-26.401). 1aㅗ edição, Rio de Janeiro - RJ, DECEX, 2017.

CAVALCANTI, P. Concurso Completo de Equitação - Global. Brasília - DF, Nobel Prol, 1993.

CAVALCANTI, P. Concurso Completo de Equitação - Subsídios. Brasília - DF, Gráfica do Exército, 2005. (2ํㅡ낭).

CAVAlCANTI, P. Concurso Completo de Equitação - Final. Brasília - DF, Poupex, 2011.

CAVALCANTI, P. Apontamentos equestres - Final. Brasília - DF, Poupex, 2017.

CONFEDERAÇÃO BRASILEIRA DE HIPISMO (CBH). Anuário CBH 2002-2003 Edição 2003. São Paulo - SP, Confederação Brasileira de Hipismo, 2003.

CONFEDERAÇÃO BRASILEIRA DE HIPISMO (CBH). Caderno de Encargos Edição 2019a. Disponível

em: <http://cbh.org.br/images/Caderno_Encargo_CBH_2018_V2.pdf>. Acesso em 14 de fevereiro de 2019.

CONFEDERAÇÃO BRASILEIRA DE HIPISMO (CBH). Calendário de CCE da CBH para ano de 2019b. Disponível em: <http://cbh.org.br/index.php/calendarioeventos-cce-2/month.calendar/2019/05/01/.html>. Acesso em 18 de fevereiro de 2019. 
CONFEDERAÇÃO BRASILEIRA DE HIPISMO (CBH). Estatuto da Confederação Brasileira de Hipismo Edição 2018a. Disponível em: < http://cbh.org.br/images/pdfs/estatuto_CBH_2018.pdf>. Acesso em 06 de fevereiro de 2019.

CONFEDERAÇÃO BRASILEIRA DE HIPISMO (CBH). Manual dos Comissários de Salto Edição 2018b. Disponível em: <http://cbh.org.br/images/ManualdeComissarios_2018.pdf>. Acesso em 13 de fevereiro de 2019.

CONFEDERAÇÃO BRASILEIRA DE HIPISMO (CBH). Quadro de oficiais de concurso de CCE 2019c. Disponível em: <http://cbh.org.br/index.php/quadro-juizescce2.html>. Acesso em 19 de fevereiro de 2019.

CONFEDERAÇÃO BRASILEIRA DE HIPISMO (CBH). Regulamento de Adestramento CBH Edição 2018c. Disponível em: $<$ http://cbh.org.br/images/Regulamento_de_Adestramento_CBH_2018.pdf >. Acesso em 10 de janeiro de 2019.

CONFEDERAÇÃO BRASILEIRA DE HIPISMO (CBH). Regulamento de CCE Edição 2006. Disponível em: <http://cbh.org.br/arquivos/Regulamento\%20CBH\%20CCE\%20-\%202006.pdf>. Acesso em: 15 de fevereiro 2018.

CONFEDERAÇÃO BRASILEIRA DE HIPISMO (CBH). Regulamento Geral Edição 2017. Disponível em: <http://cbh.org.br/images/Regulamento_Geral_CBH_2017.pdf>. Acesso em 20 de fevereiro de 2018.

CONFEDERAÇÃO BRASILEIRA DE HIPISMO (CBH). Regulamento de Salto CBH Edição 2018d. Disponível em: <http://cbh.org.br/images/Regulamento_Salto_2018_Marcacoes_20_03.pdf>. Acesso em 10 de janeiro de 2019. 
CONFEDERAÇÃO BRASILEIRA DE HIPISMO (CBH). Regulamento Veterinário Edição 2018e. Disponível em: $<$ <ttp://cbh.org.br/images/Reg_veterinario_2018_final.pdf>. Acesso em 06 de janeiro de 2019.

DUTTON, P. Modern Eventing. China, Trafalgar Square Books. 2013.

FEDERAÇÃO PAULISTA DE HIPISMO (FPH). Taxas e contribuições FPH 2019. Disponível em: <http://www.fph.com.br/artigos/taxas>. Acesso em 10 de janeiro de 2019.

FÉDÉRATION EQUESTRE INTERNATIONALE (FEI). Education Calendar Eventing 2019a. Disponível em: <https://inside.fei.org/fei/yourrole/officials/eventing/education-calendar>. Acesso em 20 de janeiro de 2019.

FÉDÉRATION EQUESTRE INTERNATIONALE (FEI). Eventing Cross-country Course Design Guidelines - Published on 18 April 2017, updates on 26 September 2018a.

Disponível em: <https://inside.fei.org/sites/default/files/FEl\%20Cross\%20Country\%20Course\%20De sign\%20Guidelines\%202018\%2026\%20September\%202018.pdf>. Acesso em 06 de janeiro de 2019.

FÉDÉRATION EQUESTRE INTERNATIONALE (FEI). Eventing Draft Schedule 2019b. Disponível em: <https://inside.fei.org/fei/yourrole/organisers/eventing/downloads >. Acesso em 15 de março de 2019.

FÉDÉRATION EQUESTRE INTERNATIONALE (FEI). Eventing Memorandum 8rd edition, updates August 2018b. Disponível em: < https://inside.fei.org/sites/default/files/FEl\%202015\%20Eventing\%20Memorandum\% 20Final\%20August\%202018.pdf>. Acesso em 12 de fevereiro de 2019.

FÉDÉRATION EQUESTRE INTERNATIONALE (FEI). Eventing Rules - 25th edition effective 1st January 2019c. Disponível em: 
<http://inside.fei.org/sites/default/files/2017\%20Eventing\%20Rules\%2030\%20March \%202017\%20-\%20changes\%20highlighted.pdf>. Acesso em: 04 de janeiro de 2019.

FÉDÉRATION EQUESTRE INTERNATIONALE (FEI). FEI Officials List - Eventing 2019d. Disponível em: <https://inside.fei.org/fei/your-role/fei-officials-lists>. Acesso em 15 de março de 2019.

FÉDÉRATION EQUESTRE INTERNATIONALE (FEI). General Regulations - 23rd edition, updates effective 1 January 2019e. Disponível em: <https://inside.fei.org/sites/default/files/GENERAL\%20REGULATIONS\%20\%20\%20Effective\%201\%20January\%202019\%20-\%20clean.pdf>. Acesso em 05 de janeiro de 2019.

FÉDÉRATION EQUESTRE INTERNATIONALE (FEI). Medical Officer \& Safety Information for health care professional 2019f. Disponível em: $<$ https://inside.fei.org/fei/your-role/medical-officer>. Acesso em 06 de fevereiro de 2019.

FÉDÉRATION EQUESTRE INTERNATIONALE (FEI). Memorandum Guidelines to Eventing Rules - 8rd edition - April 2015, updates August 2018b. Disponível em: <http://inside.fei.org/fei/regulations/eventing>. Acesso em 04 de janeiro de 2019.

FÉDÉRATION EQUESTRE INTERNATIONALE (FEI). Technical Delegate Report Eventing 2019g. Disponível em: <https://inside.fei.org/fei/yourrole/officials/eventing/forms>. Acesso em 02 de fevereiro de 2019.

FERREIRA, R. História do Hipismo Brasileiro. São Paulo, Antônio Bellini Editora e Design, 1999.

FOOD AND AGRICULTURE ORGANIZATION OF THE UNITED NATIONS (FAOSTAT). Download Data - Brazil - Horses - 2018. Disponível em: <http://www.fao.org/faostat/en/\#data/QA >. Acesso em 15 de abril de 2018. 
LABORATÓRIO PADDOCK. Exames de AIE e Mormo. Disponível em:<http://www.laboratoriopaddock.com.br/pagamentos/>. Acesso em: 17 janeiro 2019.

LIMA, R. A. S.; CINTRA, A. G. Revisão do Estudo do Complexo Agronegócio Cavalo. Brasília: Câmara de Equideocultura do Ministério da Agricultura, Pecuária e Abastecimento, 2015.

LIMA, R. A. S.; SHIROTA, R.; BARROS, G. S. C. Estudo do complexo agronegócio cavalo. Piracicaba: ESALQ/USP, 2006.

MCCANN, F. D. Soldados da Pátria - História do Exército Brasileiro 1889 1937. São Paulo, Editora Schwarcz, 2007.

OLYMPIC SOLIDARITY. Managing Olympic Sport Organisations. United States of America, Human Kinects, 2007.

MORGADO, F. B. ADESTRAMENTO DO CAVALO. São Paulo - SP, Editora Nobel S.A, 1990.

PAYNE, M. A virada olímpica: como os Jogos Olímpicos tornaram-se a marca mais valorizada do Mundo. 1ํㅡㄹ Eção, Rio de Janeiro, Casa da Palavra, 2006.

POIT, DAVI RODRIGUES. Organização de eventos esportivos. $5^{\text {a }}$ Edição, São Paulo, Phorte Editora, 2013.

UNITED STATES EVENTING ASSOCIATION. Cross-country Obstacle Design Guidelines, 2012. Disponível em:< https://useventing.com/sites/default/files/xc obstacle guidelines.pdf $>$. Acesso em: 16 janeiro 2019. 
WORLD HEALTH ORGANIZATION - WHO; FOOD AND AGRICULTURE ORGANIZATION OF THE UNITED NATIONS - FAO. Rapport sur la primière session. Groupe mixte OMS/FAO d'experts em zoonoses. Genève: OMS, 1951.

YIN, Robert K. Estudo de Caso: Planejamento e Métodos. Porto Alegre: Bookman, 2006. 